SOBRE

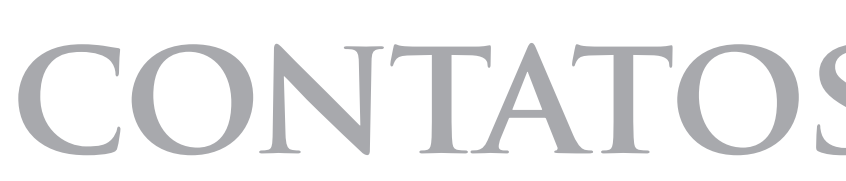

FRONTEIRA

UM ENFOC

ARQUEOLÓGI 


\section{SOBRE CONTATOS E FRONTEIRAS: UM ENFOQUE ARQUEOLÓGICO}

\section{R I S T I A N E MART I N S}

UNIVERSIDADE FEDERAL DO PARÁ, BRASIL 


\title{
SOBRE CONTATOS E FRONTEIRAS: UM ENFOQUE ARQUEOLÓGICO
}

\section{Resumo}

Esse artigo propõe uma discussão sobre contatos culturais na região Amazônica no período pré-colonial. Para debater esse tema, utilizarei informações etnohistóricas e dados arqueológicos obtidos por pesquisas realizadas na região do baixo Tapajós, confrontando-os com outros contextos do baixo Amazonas, a fim de fundamentar a hipótese de interações culturais em escala regional sugerida pela ampla distribuição da cerâmica do Horizonte Inciso-Ponteado. Os dados indicam que grupos sociais interagiram no passado compartilhando redes de comunicação, ideias e cosmologias. Isso é percebido através do estudo da cultura material produzida e significada socialmente, a qual é entendida como indicador de vínculos sociais que transpunham fronteiras geográficas, bem como veículo de identidade cultural e agente ativo de pertencimento social. São apresentadas similaridades e distinções entre grupos que ocuparam a região em questão a partir da comparação das características de implantação dos sítios arqueológicos na paisagem e da cultura material, utilizando como estudo de caso a cerâmica do sítio arqueológico Alvorada, município de Itaituba, Pará.

Palavras-chave: Arqueologia do baixo rio Tapajós, cultura material, interações culturais e fronteiras.

\section{ON CONTACTS AND BORDERS: AN ARCHAEOLOGICAL APPROACH}

\begin{abstract}
This article proposes a debate on cultural contacts in the Amazon region in pre-colonial times. Ethnohistorical information and archaeological data obtained through surveys conducted in the lower Tapajós river are confronted with other contexts in the lower Amazon, in order to substantiate the hypothesis that the wide distribution of the Incised-and-Punctate ceramics indicate regional cultural interaction between social groups in a cultural network of shared cosmologies. This is realized through the study of material culture socially produced and signified, which is understood as an indicator of social ties that transposed geographical boundaries, were vehicles of cultural identity, and active agents of social belonging. Similarities and differences between groups that occupied the region are examined through landscape use patterns and material culture, using the ceramics from the Alvorada archaeological site in the city of Itaituba, Pará, as a case study.
\end{abstract}

Keywords: Archaeology of the lower Tapajós river, material culture, cultural interactions and boundaries. 


\section{SOBRE CONTACTOS Y FRONTERAS: UN ENFOQUE ARQUEOLÓGICO}

\section{Resumen}

Aquí proponemos una discusión acerca de los contactos culturales en la región amazónica en el periodo pre-colonial. Para discutir este tema, son utilizados los datos de información etnohistórica y arqueológica obtenidos a partir de prospecciones realizadas en el bajo rio Tapajós confrontándolos con otros contextos en el bajo Amazonas, con el fin de corroborar la hipótesis de que la amplia distribución de la cerámica del Horizonte Inciso-Punteado Horizonte atesta interacciones culturales a escala regional. Los datos indican que los grupos sociales interactúavan en una red que incluya el intercambio de ideas y cosmologías. Esto se realiza a través del estudio de la cultura material producida y significada socialmente, lo que se entiende como un indicador de las relaciones sociales de transposición de las fronteras geográficas, así como un vehículo de la identidad cultural y el agente activo de pertenencia social. Se presentam similitudes y diferencias entre los grupos que ocuparon la región, por la comparación de las características de ubicación de sitios arqueológicos en el paisaje y la cultura material, utilizando como caso de estudio la cerámica del sitio arqueológico Alvorada, en la ciudad de Itaituba, Pará.

Palabras-clave: Arqueología del bajo río Tapajós, cultura material, interacciones culturales y fronteras 


\section{CONTATOS E FRONTEIRAS NA ARQUEOLOGIA}

Em arqueologia, as interações culturais são comumente debatidas à luz da cultura material, que é usada ainda para tratar da dispersão de grupos sociais no passado. Em meados do século XX foram propostos para a arqueologia brasileira os conceitos de fase e tradição arqueológicas para explicar a dispersão de traços tecnológicos e estilísticos similares de materiais culturais com persistência no tempo e espaço (Meggers e Evans 1961).

Atributos tecnológicos foram utilizados por Meggers e Evans (1961) para propor um modelo de ocupação e definir áreas culturais na Amazônia, que resultou na identificação de quatro grandes horizontes culturais: Hachurado-Zonado, Borda Incisa, Polícromo e Inciso-Ponteado, que posteriormente foram referidos como tradições. Partindo da premissa de origens exógenas das cerâmicas com decorações complexas encontradas na região Amazônica, Meggers e Evans (1961) sugeriram que movimentos de difusão cultural com origem nos Andes, América Central e Guianas foram responsáveis pela introdução desses artefatos com decorações originais e diversificadas.

A exemplo da cerâmica do denominado Horizonte Inciso-Ponteado, Meggers e Evans (1961:381) postularam que a distribuição desse estilo incluía a bacia dos rios Orinoco e Amazonas, além de ocorrências nas Guianas. Seus principais traços característicos eram padrões decorativos compostos por in- cisões e ponteados em faixas ao redor de vasilhas, linhas geométricas paralelas, além de adornos e apliques de formatos antropomorfos e zoomorfos. Sobre as técnicas de produção dos artefatos cerâmicos, informaram que localmente (na bacia do rio Amazonas), o antiplástico predominante era o cauixi, um espongiário fluvial, associado a caco moído, areia e rocha triturada (Meggers e Evans op. cit.).

Nas décadas posteriores, várias críticas foram dirigidas à aplicabilidade do modelo da ecologia cultural, especialmente na região Amazônica (Carneiro 2007; Roosevelt 1987, Roosevelt et al. 1991, 1992, 1996). Argumentos contrários à proposta de origens exógenas das cerâmicas amazônicas vêm acrescentando dados importantes que atestam a produção local desses conjuntos cerâmicos, bem como diversas variações internas nas fases e tradições propostas por Meggers e Evans (1961). Tais estudos argumentam que o pequeno número de atributos utilizados para as seriações, assim como os métodos de investigação que produziram esses primeiros modelos de ocupação na região, não são suficientes e adequados para explicar mudanças culturais, diferentes organizações sociais, e suas implicações na cultura material (Machado 20052006; Schaan 2007a, 2007b).

Diante disto, faz-se necessária a reformulação e reinterpretação de conceitos caros à arqueologia como interação cultural e fronteira, em sua relação com a cultura material.

Recentemente, estudos de estilos cerâmicos tem buscado o entendimen- 
to de diferentes expressões culturais locais, porém consideradas como articuladas em contextos regionais (Barreto 2008; Schaan 2007a, 2007b, 2012).

Para exemplificar algumas dessas abordagens, destacam-se estudos realizados com indústrias cerâmicas do período considerado de maior adensamento populacional e complexidade cultural, a partir do primeiro milênio da era cristã, a exemplo das cerâmicas tapajônica e marajoara, conhecidas por sua estética complexa (Barreto 2008; Schaan 2007a, 2007b, 2012).

Em publicação recente, Schaan (2012) faz uso da cultura material e de estratégias de uso da paisagem para debater indicadores de interações culturais em escala regional ao longo do planalto de Belterra, das áreas de várzea do rio Tapajós, e ao longo dos rios Nhamundá e Trombetas. Tais indicadores na cultura material se referem às similaridades na produção de artefatos cerâmicos e líticos. Já com relação à ocupação da paisagem, Schaan (op. cit.) sugere que os sítios possuem um padrão de assentamento marcado pela implantação em áreas elevadas (serras e platôs), áreas ribeirinhas e de terra firme, com presença tanto de assentamentos permanentes como áreas de atividades relacionadas à pesca e captação de recursos diversos. Destaca, ainda, o manejo de lagos situados entre a várzea e a terra firme como uma prática regional comum no baixo Amazonas (Schaan 2012). Para a pesquisadora, o conjunto dessas práticas reflete um contexto regional de ocupação que será mais bem entendido com a articu- lação de diferentes contextos em uma escala ampla.

Em outro artigo, Schaan (2007a) sugere que grupos pré-coloniais que habitaram a região leste da ilha de Marajó exerceram controle sobre os recursos aquáticos, o que teria influenciado sua distribuição geográfica, conformando diversos agrupamentos regionais (cacicados), ao invés de um grande grupo homogêneo politicamente. Tais unidades políticas teriam justificado seus domínios territoriais com base na ancestralidade de seres humanos e míticos, e suas fronteiras territoriais não poderiam ser lidas a partir de uma forma única e regular de produzir a cerâmica cerimonial.

A autora propõe uma abordagem de estilos cerâmicos que ultrapassa a correlação (equivocada) entre cultura material e etnia, sugerindo que diferentes formas de produzir os artefatos podem, por exemplo, materializar diferenças internas em um mesmo grupo social, explicadas por diferentes relações com o mundo simbólico e ritualístico. Esta ideia contribui para o entendimento de que um determinado grupo social pode se utilizar de meios simbólicos e estéticos para consolidar sua coesão social e justificar seus limites em relação aos "outros".

Outro exemplo de uso da cultura material para entender expressões culturais locais articuladas em contexto regional é apresentado por Barreto (2008), que estudou a estética de artefatos com decorações complexas, especialmente das urnas funerárias marajoaras, cuja investigação, para a pesquisadora, 
pode contribuir de forma profícua para o entendimento de diferenças na organização social entre sociedades amazônicas.

Utilizando-se de conceitos da antropologia social e da antropologia da arte sobre estilo e agência (especialmente Gell 1992), Barreto (2008) argumenta que as técnicas de encantamento empregadas para a produção das urnas funerárias marajoara dotam estes artefatos de poder de mediação e transformação das relações sociais, constituindo-as em corpos passíveis de experiências sensoriais que afetam diretamente as dinâmicas culturais de identidade coletiva, comunicação e concepções cosmológicas de seus produtores.

Barreto não está interessada em destacar as representações simbólicas da estética da cerâmica marajoara, e sim pensar sobre o poder destes artefatos na formulação de regras e comportamentos sociais. Em seus termos:

"Este caminho diverso consiste em transferir a ênfase da análise do significado simbólico dos objetos para a agência dos objetos, isto é investigar a capacidade destes objetos de intermediarem ações sociais. Nesta perspectiva, questiona-se menos o que o objeto representa e mais o que ele "faz" e como "age" na rede de relações sociais destas antigas culturas... Por isso, a esfera de agências dos objetos aqui escolhida, foi a esfera dos rituais funerários, onde ao mesmo tempo em que valores tradicionais são reatualizados através de manifestações artísticas de variada natureza, eles podem também ser transformados" (2008:25).
Com esta assertiva, propõe uma abordagem que transcenda o significado simbólico da iconografia, somando a este a relação entre padrões estilísticos, cosmologias indígenas, organização social e articulação regional.

A variabilidade e elaboração das técnicas de encantamento dos objetos envolvidos em festas, rituais e cerimônias coletivas são destacadas pela autora pelo intenso uso social da estética como marcador de identidade e pertencimento a coletivos regionais que transitavam para uma "sociedade mais complexa" (2008:208). Neste sentido, entende os objetos como pessoas, dada a sua intensa capacidade (agência) de interrelacionar sujeitos.

A autora conclui que sua escolha pela abordagem da agência das urnas marajoara the possibilitou identificar o imenso potencial analítico de objetos ritualísticos, especialmente os funerários, para o entendimento de questões como: morte, corpo, alma e as materialidades envolvidas nestas - e por estas - concepções indígenas (Barreto 2008).

No campo da antropologia, as questões de interações culturais e suas fronteiras estão diretamente relacionadas à discussão sobre grupos étnicos e etnicidade, tal como se observa nos trabalhos de Fredik Barth (1976a), um dos maiores expoentes sobre o tema. O antropólogo, ao realizar pesquisa etnográfica entre grupos ocupantes da Oceania, sudeste da Ásia e da África, investigou a construção de identidades étnicas e a função do "outro" nesse processo. 
Para Barth (1976a), a construção das identidades é feita pelos seus próprios atores com base em seus "sinais diacríticos", objetivando organizar as interações sociais, o que não implica ausência de contatos sociais; pelo contrário, destes dependem de uma série de trocas que estabelecem a posição do "eu" e do "outro" nos contatos culturais. Neste sentido, afirma que identidades não são estáticas, e sim transformadas a partir de diferentes contextos:

"El hecho de que un grupo conserve su identidad, aunque sus miembros interactúen con otros, nos ofrece normas para determinar la pertenencia al grupo y los medios empleados para indicar afiliación o exclusión. Los grupos étnicos no están basados simple o necesariamente en la ocupación de territorios exclusivos; necesitamos analizar los diferentes medios por los cuales logran conservarse, pues, no es sólo mediante un reclutamiento definitivo, sino en virtud de una expresión y una ratificación continuas"(1976a:7).

Com isto, o antropólogo infere que as fronteiras são cultivadas apesar do intercâmbio entre os diversos atores sociais constituindo-se em espaços de auto-afirmação (Barth 1976a).

$\mathrm{Na}$ arqueologia, considerando a cultura material como o principal vetor de interlocução, algumas abordagens de Barth (ainda que o mesmo não tenha se detido nos objetos etnográficos), podem ser extrapoladas para contextos pré-coloniais quando se considera que as coisas (aqui entendidas como os artefatos produzidos e significados socialmente) participam ativamente do processo de construção de identidades (Barreto 2008).

$\mathrm{Na}$ região do baixo rio Tapajós e baixo rio Amazonas, por exemplo, tal como demonstrado por Schaan (2012), características de uso da paisagem e da cultura material podem ser utilizadas para sugerirmos interações culturais em escala regional (Schaan 2012, Martins 2012). Acredito que neste espaço compartilhado por grupos sociais distantes geograficamente seja pertinente a perspectiva de Barth quanto às fronteiras e os contatos culturais. Ainda que não se pretenda a concepção da etnicidade neste estudo de caráter arqueológico (e isto, por certo, não é o interesse), tal ponto de vista pode provocar diferentes perguntas necessárias a estudos mais amplos sobre a cultura material.

Objetivando aprofundar o tema, esse artigo apresenta alguns dados etnohistóricos e arqueológicos obtidos para a região do baixo curso do rio Tapajós, especialmente sobre as características de implantação de sítios arqueológicos na paisagem e seus artefatos cerâmicos. A pesquisa investiga, mais detidamente, um sítio arqueológico localizado no que seria o limite sul da região de dispersão do Horizonte Inciso-Ponteada no baixo curso do rio Tapajós e apresenta os resultados alcançados à luz dos demais dados e as hipóteses que vem sendo discutidas sobre a ocupação indígena pré-colonial da região. Estudos realizados nos últimos anos vêm revelando que a área de dispersão de sítios arqueológicos ligados a essa tradição é maior do que se pensava anteriormente (ver 
Stenborg et al., neste volume).

Para tanto, realiza-se dois exercícios: 1) o primeiro de escala local, com foco no sítio arqueológico Alvorada e; 2) o segundo de escala regional, correlacionando este estudo de caso ao conjunto dos demais contextos já identificados nas adjacências.

Aqui, tentarei demonstrar como esses dados, ainda que pontuais diante do grande potencial arqueológico da região, podem ser articulados com noções de contatos culturais e, principalmente, sobre o papel ativo da cultura material em estreitar vínculos sociais a largas distâncias.

\section{ESPAÇO DA PESQUISA}

O recorte espacial deste estudo é a região do baixo curso do rio Tapajós, especificamente o município de Itaituba, no sudoeste do estado do Pará, onde foram registrados diversos sítios arqueológicos quando da realização de um Programa de Arqueologia Preventiva em trechos da BR-163 e BR-230, executado pelo Núcleo de Pesquisa e Ensino de Arqueologia (NPEA) da Universidade Federal do Pará, e coordenado por Denise Schaan (PPGA/ UFPA), com financiamento do DNITDepartamento Nacional de Infraestrutura de Transportes.

\section{CONTEXTO ETNOHISTÓRICO E ARQUEOLÓGICO}

Diferentemente de outras áreas arqueológicas na Amazônia, há diver- sas informações etno-históricas sobre os grupos indígenas que habitavam a região da confluência dos rios Tapajós e Amazonas nos primeiros séculos da conquista (Teixeira 1639; Bettendorf 1698; Berredo 1718; Carvajal 1941 [1542]; Nimuendaju 1949; Heriarte 1964; Ursua e Aguirre apud Porro 1993; Acuña 1994 [1641]). Breves descrições de festas, ritos, aspectos do cotidiano, estruturas de aldeias, rituais mortuários, fontes de alimentação, relações familiares, redes de trocas comerciais, religião e guerras são fornecidas, principalmente, por missionários e indivíduos ligados à administração colonial, não raro sob uma ótica eurocêntrica que camuflava pretensões de escravização dos indígenas e/ou exploração econômica dos recursos naturais. Tendo em vista a natureza e contexto histórico dessas informações, as mesmas devem ser tomadas com rigor metodológico, e confrontadas com os dados arqueológicos.

As informações apresentadas a seguir objetivam esclarecer sobre o grande adensamento populacional indígena à época do contato com os europeus, e fazem diversas referências a articulações comerciais, políticas e ideológicas praticadas por grupos indígenas na região do baixo rio Amazonas e baixo rio Tapajós.

Segundo a crônica do padre Gaspar de Carvajal (1941 [1542]), por exemplo, quando da expedição do espanhol Francisco de Orellana, que percorreu o rio Amazonas até sua foz no século XVI, a confluência deste curso d'água com a foz do rio Tapajós era habitada por índios "arredios" que os atacaram atirando flechas envenenadas, levando-os a se- 


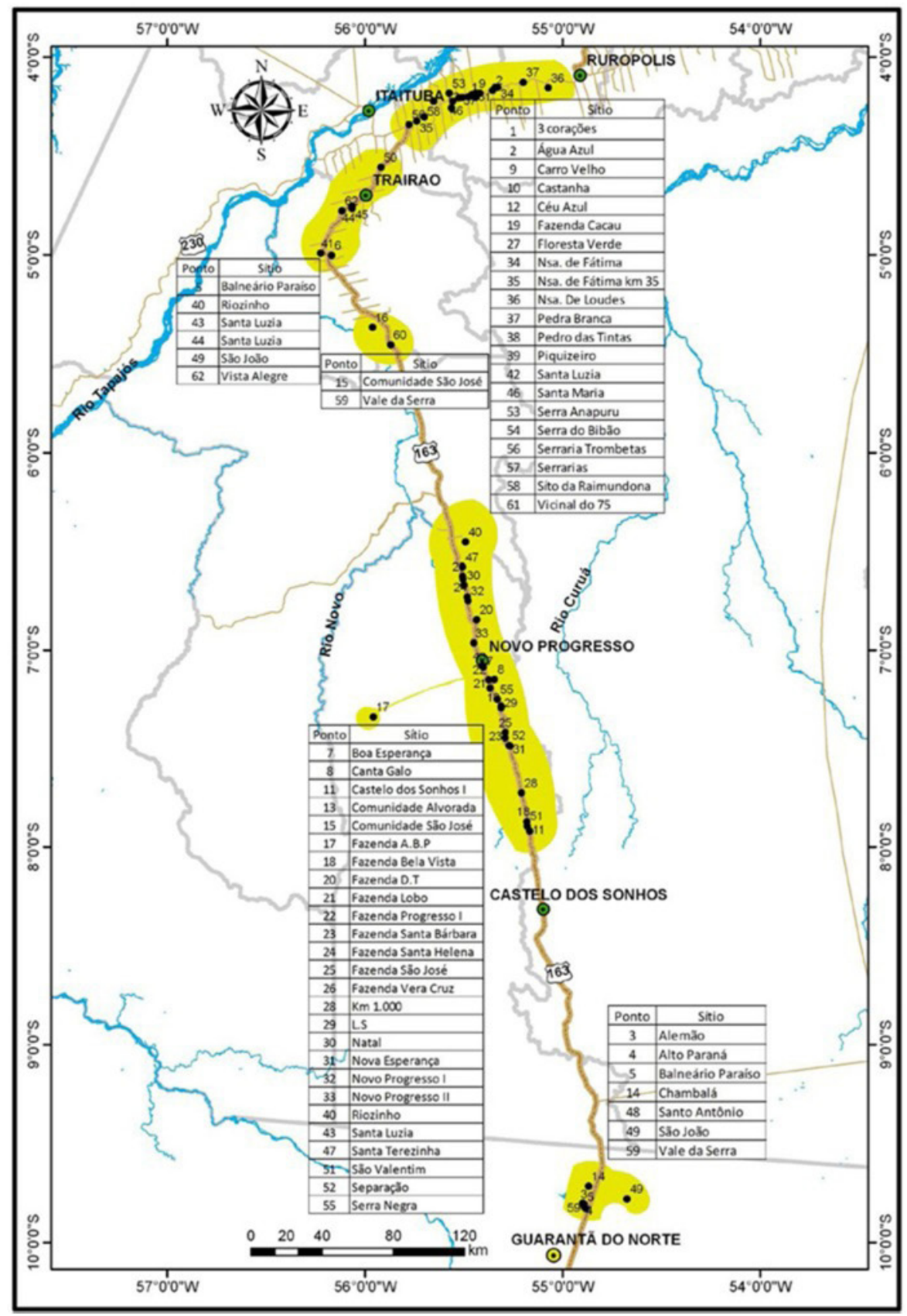

Figura 1 - Sítios localizados nas rodovias BR-163 e BR-230 pelo Programa de Arqueologia. No município de Itaituba, particularmente no trecho da rodovia BR-230 (Transamazônica) que o liga ao município de Rurópolis, foram localizados 26 sítios e quatro ocorrências pontuais de vestígios arqueológicos. São sítios de terra preta a céu aberto, oficinas líticas e gravuras rupestres. 


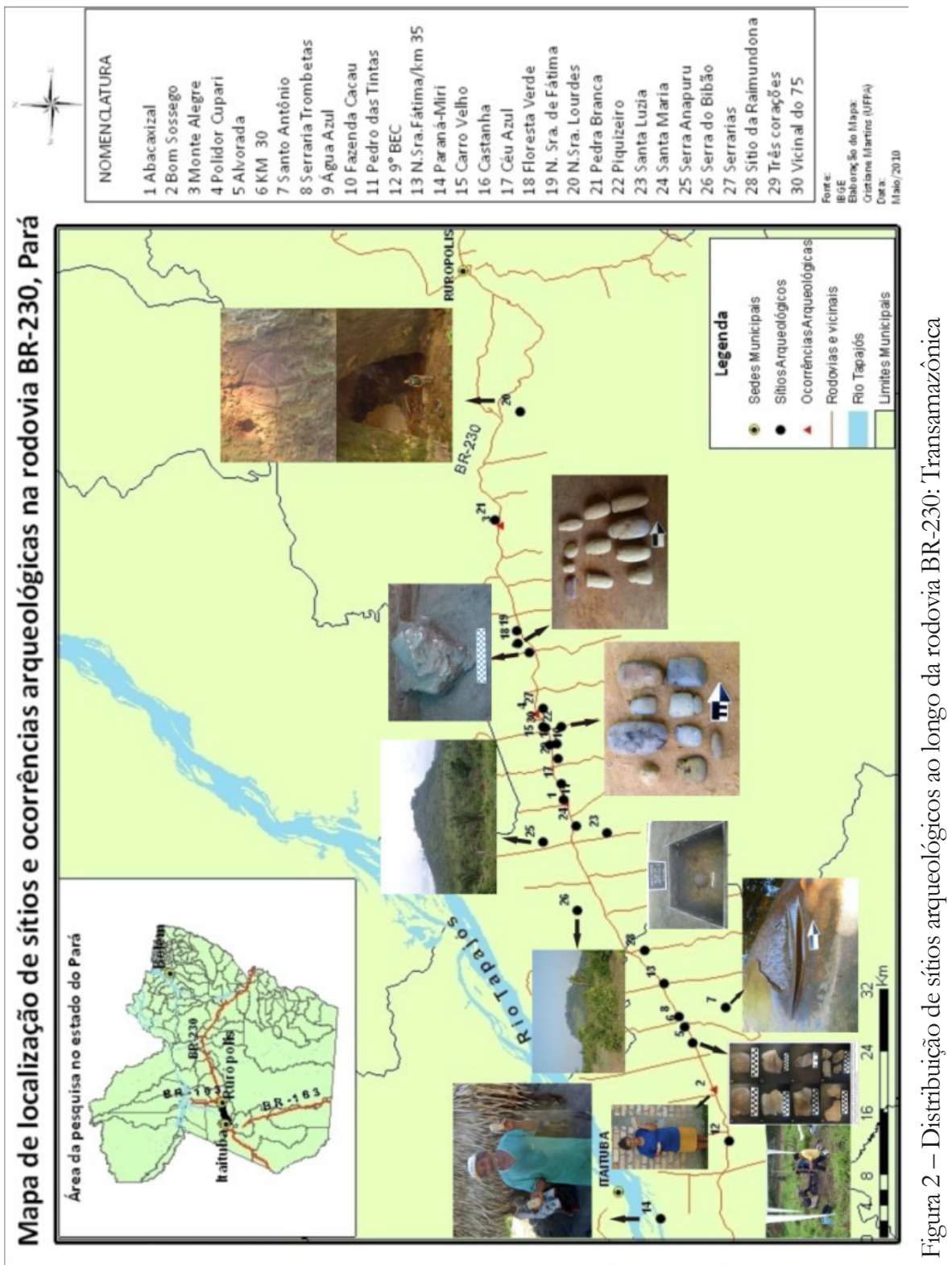


guirem viagem pela margem oposta do rio Amazonas, menos povoada (Carvajal 1941 [1542]; Nimuendaju 1949).

Duas décadas depois, em 1561, Pero de Ursua e Aguirre empreenderam a segunda incursão espanhola no rio Amazonas, que resultou em quatro crônicas complementares (Altamirano, Monguia, Vásquez e Zúñiga), e que relatam a existência de um grupo populoso um pouco abaixo do estreito de Óbidos, denominados de Arauquinas. Segundo eles, havia ali grupos que praticavam a antropofagia em casas e lugares próprios para a idolatria de seus mortos (Ursua e Aguirre apud Porro 1993).

A partir do século XVII, a coroa portuguesa realizou diversas incursões pelos rios da região a fim de expandir suas frentes de exploração econômica para além do estuário amazônico, onde estrangeiros mantinham relações de troca com populações indígenas (Reis 1993, 2003). A primeira dessas incursões foi chefiada por Pedro Teixeira em 1626, que manteve contato com grupos indígenas (os Tapuvas) assentados na confluência do rio Amazonas com o Tapajós, e daí adentrou o rio Tapajós onde, provavelmente na altura de Alter do Chão, esses grupos estariam aldeados (Berredo 1718). Alguns anos depois, Pedro Teixeira realizou uma segunda expedição pelo rio Amazonas em direção ao Peru, e no seu retorno descreveu os Tapuvas como índios guerreiros que usavam flechas envenenadas, que praticavam a antropofagia e possuíam escravos originários de grupos vizinhos, com os quais também realizavam comér- cio a longas distâncias (Teixeira 1639).

As crônicas de Cristóbal de Acuña (1641) e de Maurício de Heriarte (1964) também reuniram informações provenientes da excursão de Pedro Teixeira a Iquitos, Peru. Segundo o relato de Acuña, os índios Tapajoses eram temidos guerreiros, inclusive pelos portugueses, uma vez que, muito numerosos, eram hábeis no uso de flechas envenenadas mortais. Informou ainda sobre a comercialização das "buraquitas" (os muiraquitãs), bens de alto valor, com outras nações do entorno (Acuña 1994 [1641]).

Heriarte (1964) destacou a hierarquia social entre os Tapajó, os quais teriam um centro político sediado na confluência dos rios Amazonas e Tapajós, onde hoje está implantada a sede da cidade de Santarém. Segundo Heriarte, a este centro administrativo estavam subordinadas outras chefias menores distribuídas pelas adjacências. Além disso, fez referências a outros grupos indígenas ocupando o rio Trombetas (os Cunuris ou Conduris, além de outros), que mantinham contato com os Tapajó e possuíam uma organização social similar, possuindo seu próprio governo, cerimônias e "ídolos". Também fez referências lacônicas a outros grupos indígenas no rio Tapajós, como os Marautus, Caguanas e Orurucuros (Heriarte 1964).

Segundo Cristóbal de Acuña, os portugueses teriam atacado os índios Tapajós no ano de 1639, sob o comando de Bento Maciel, em busca de escravos (Acuña 1994 [1641]). A catequização dos indígenas inicia em 1661, quando o padre João Felipe Bettendorf é incumbido por Antônio Vieira de fun- 
dar uma missão religiosa na aldeia dos Tapajós. Bettendorf (1698), durante sua estada na foz do Tapajós, registrou alguns aspectos da organização social indígena, mencionando a existência de estratos sociais. Relatou ainda que os Tapajós possuíam casas escondidas na mata onde cultuavam seus mortos, guardando os restos mumificados daqueles de maior prestígio social, os quais eram reverenciados em celebrações ritualísticas e mantidos como oráculos. Os portugueses acabaram por, violentamente, destruir as múmias que eles guardavam, na tentativa de impedir tais cerimônias, que consideravam demoníacas (Bettendorf 1698). Já de acordo com o relato de Heriarte (1964), os mortos seriam cremados e suas cinzas consumidas dissolvidas em bebidas.

No século XVIII, acentuou-se na região do baixo rio Amazonas um processo intenso de exploração extrativista e escravização indígena (esta última iniciada já desde os primeiros contatos com a colônia portuguesa). Com a expulsão dos jesuítas em 1759 (desde 1668 haviam-se instalando diversas missões no rio Tapajós), as antigas missões foram elevadas a vilas e lugares, tal como a Vila de Santarém, criada em 1754. Nessa época, esses locais passaram a compor grandes pólos de povoamento, desenvolvimento agrícola e comercial da administração pombalina e extrativismo (Menéndez 1981-82:307-8).

Em virtude desse interesse econômico crescente, diversas expedições foram realizadas nos séculos XVIII e XIX ao rio Tapajós, objetivando registrar os recursos naturais da região (Barbosa Rodrigues 1875; Florence 1977; Bates 1979), delimitar os limites administrativos do estado do Pará (Coudreau 1977), além daquelas de cunho científico (Condamine 1743). O cientista e explorador francês Charles-Marie de La Condamine desceu o rio Amazonas partindo do Peru, interessado na geografia da região, na fauna e flora, nas antigas lendas indígenas do rio, bem como nos muiraquitãs produzidos pelos índios Tapajós. Ele registra na ocasião a interligação entre os rios Amazonas e Orinoco pelo canal do Cassiquiare (Condamine 1743).

As primeiras informações arqueológicas sobre a região foram geradas pelo botânico João Barbosa Rodrigues (1875), que percorreu o rio Tapajós realizando um inventário da flora, inicialmente focado nas palmeiras, mas que se estendeu a diversos tipos de plantas, como as de efeito curativo, sempre interessado nas informações dos indígenas sobre a flora. Aproveitou para fazer coletas arqueológicas que lhe induziram a projetar a expansão do domínio Tapajônico até a cachoeira do Boruré, localizada próximo a Itaituba.

Em 1870, o geólogo Frederick Hartt (1885) realizou escavações no sambaqui da Taperinha, localizado no paranamirim do Ayayá, afluente da margem direita do rio Amazonas, 40km a leste de Santarém, onde coletou fragmentos de ossos, carvões e cerâmica, sendo a maioria sem decoração, e poucos fragmentos com incisões, além de identificar sítios com terra preta, a qual inicialmente atribuiu uma origem natu- 
ral. Contudo, em uma segunda investigação no sambaqui, um ano depois, encontrou artefatos cerâmicos naquele solo escuro, o que lhe sugeriu a origem indígena daquele material (Hartt 1885). O geólogo também menciona outros sítios situados em áreas elevadas e serras circunvizinhas à Taperinha, onde também ocorria a terra preta.

Com relação à cultura material dos "moradores dos altos", informou a presença de artefatos ornamentados, rodelas de fuso e estatuetas de forma humana. A cerâmica, segundo o geólogo, era composta por material decorado com impressão de dedos, não ornamentadas, ou "lastrada com barro branco e pintada", além dos fragmentos de apliques modelados na forma de animais, e fragmentos de cabeças, pés, e braços de "ídolos", semelhantes aos encontrados no Marajó (1885:13). Esta caracterização cerâmica foi estendida para as demais localidades investigadas por ele, tais como Itaituba, Diamantina, Panema e Ipaupixuna, que foram consideradas como ocupadas por grupos tapajônicos.

Hartt localizou ainda uma série de urnas funerárias em Itaituba, na localidade denominada Cafezal, na margem esquerda do rio Tapajós, "atraz de uma grande ilha arborizada, umas cinco ou seis milhas abaixo da villa de Itaituba" (1885:15). Esta localidade, a qual denominou de Estação Funerária de Cafezal, apresentava um padrão de sepultamento com diversas urnas cerâmicas que foram quebradas em ocasião do nivelamento do terreno feito pelo seu proprietário, Sr. Castillo.
As investigações de Barbosa Rodrigues (1875) e Hartt (1885), ainda que de naturezas diferenciadas, sugeriram que a área que compreendia a foz do rio Tapajós até a Cachoeira do Boruré, a $40 \mathrm{~km}$ acima de Itaituba, esteve sob a influência dos índios que habitavam a foz do rio, os Tapajó. Essas inferências foram produzidas a partir da presença de solos férteis, cerâmica com pintura vermelha e com adornos modelados semelhantes aos encontrados na cidade de Santarém e no sambaqui da Taperinha.

Entre 1923 e 1926, o etnólogo Curt Nimuendaju (1949; Stenborg 2004) localizou 65 sítios com terra preta em Santarém, Alter do Chão e Samaúma, em Arapixuna, no Lago Grande de Vila Franca, e margem direita do rio Amazonas, entre a boca deste lago e a do Arapixuna. A partir de suas pesquisas de campo, Nimuendaju (1949) propôs que o domínio tapajônico estendia-se até, aproximadamente, $50 \mathrm{~km}$ ao sul de Santarém, na localidade de Aramanahí, onde encontrou sítios afastados dos rios principais e em áreas elevadas com poços possivelmente cavados por grupos indígenas antigos.

O etnólogo sugeriu que a origem da cultura material encontrada distribuída por essa região seria encontrada na parte meridional da América central, uma vez que o estilo das cerâmicas desta região se assemelha em grande medida, levando em consideração o uso de vasos trípodes, as formas de rãs subindo pela parte superior dos vasos, o motivo "mão no rosto", entre outros (Nimuendaju 1949).

Nas décadas posteriores (de 1940 e 
1970), a ênfase dos estudos sobre a ocupação humana do baixo Amazonas esteve voltada para a caracterização estilística da cultura material tapajônica, a partir do estudo de coleções museológicas reunidas desde o século XIX (Palmatary 1939, 1960; Frederico Barata 1950, 1951, 1953a, 1953b, 1954; Corrêa 1965). Palmatary (1939, 1960) realizou a caracterização estilística da cerâmica Tapajônica, propondo uma classificação, e explorou prováveis rotas de dispersão que interligavam a foz do rio Tapajós ao Caribe, via rio Orinoco.

Já os estudos de Frederico Barata (1950, 1951, 1953a, 1953b, 1954), a partir de suas escavações e coletas no bairro Aldeia, em Santarém, resultaram em descrições minuciosas daquele estilo cerâmico e das representações dos seus elementos zoomorfos e antropomorfos. De especial interesse são suas observações sobre o caráter representacional dos motivos geométricos, que imitariam seres da fauna local. Este autor identificou cachimbos de cerâmica que teriam sido produzidos a partir do contato com os colonizadores portugueses, pois seus traços estilísticos diferiam daqueles da cerâmica Tapajônica e sugeriam uma inovação tecnológica local derivada das relações de contato. Já Corrêa (1965) propõe uma descrição tipológica das estatuetas antropomorfas e zoomorfas, apontando para a possibilidade de migrações pelo rio Amazonas que poderiam responder pela expansão do estilo Tapajônico.

$\mathrm{Na}$ década de 1970 ocorreram alguns levantamentos arqueológicos no rio Tapajós bem como no baixo Amazonas, realizados por arqueólogos como
Ulpiano Meneses e Celso Perota, vinculados ao Programa Nacional de Pesquisas Arqueológicas na Bacia Amazônica (PRONAPABA). Entre os anos de 1971 e 1973, Ulpiano Meneses realizou prospecções em Prainha e Santarém, localizando 25 sítios arqueológicos próximos a lagoas e ocupando áreas limítrofes entre a várzea e terra firme, tendo identificado ainda estradas que os interligavam (Simões e Araújo-Costa 1978). Já Celso Perota prospectou as margens do rio Tapajós até os seus formadores, na confluência dos rios Juruena e Teles Pires (Perota 1979, 1882). Em 1979 e 1982, Perota localizou 33 sítios arqueológicos. $\mathrm{Na}$ primeira campanha de campo, realizada em 1979 (terceiro ano do PRONAPABA), a área abrangida correspondeu à foz do rio Curi, aproximadamente no limite entre Itaituba e Aveiro, até uma área acima do rio Jamanxim. Neste trecho foram encontrados 21 sítios arqueológicos às margens do rio Tapajós; entre os vestígios arqueológicos havia grande incidência de material cerâmico do Horizonte Inciso-Ponteado, ocorrência pontual de cerâmica tapajônica, constante presença de fragmentos com pintura polícroma e excisões, sítios com sepultamentos secundários em urnas cerâmicas, terra preta, além de diversos machados de pedra em quase todos os sítios registrados (Perota 1979).

$\mathrm{Na}$ segunda etapa de campo realizada em 1982 foi investigada a área compreendida entre Jacareacanga até a confluência dos rios Juruena e Teles Pires, onde foram localizados 12 sítios arqueológicos. Os artefatos presentes 
nestes sítios também foram atribuídos ao Horizonte Inciso-Ponteado e a outro tipo de cerâmica sem decoração que, todavia, não havia sido estudada e definida, a qual Perota sugere pertencer aos índios Mundurucú, que dominavam a região (Perota 1982).

Com base nas descrições dos sítios localizados nos dois trechos investigados e sua cultura material, Perota informa que em uma área mais acima do rio Jamanxim, a cultura material é mais diversificada, ocorrendo artefatos típicos da cerâmica Santarém (nos sítios Castanheiro e Santarenzinho - este último registrado na localidade de mesmo nome -, ambos na margem direita do rio Tapajós). Já no segundo trecho, até o alto curso do rio Tapajós, o material arqueológico era bem mais simples, sem a presença de urnas com enterramentos e terra preta, somente cerâmica simples e artefatos líticos (1982). Estes dados parecem apontar para uma área de limite de ocorrência de influência dos grupos da foz do rio, os Tapajó.

Partindo destas informações, reitera-se a presença de cerâmica do Horizonte Inciso-Ponteado na região do baixo curso do rio Tapajós e pode-se inferir que o setor de cachoeiras do rio Tapajós (próximo à atual sede do município de Itaituba) possa ter correspondido a um divisor geográfico natural entre os grupos portadores da cerâmica do Horizonte Inciso-Ponteado e os grupos associados a contextos do Brasil Central (Perota 1979, 1982).

Em 1992, uma equipe de pesquisadores do Museu Paraense Emílio Goeldi (MPEG) realizou escavações em Itaituba, identificando que a cidade está assentada sobre um grande sítio arqueológico. Foi encontrado material cerâmico, lítico e urnas funerárias ocorrendo em superfície e até $70 \mathrm{~cm}$ de profundidade da camada de ocupação. Através da datação radiocarbônica de material orgânico associado a duas urnas, obtiveram datações que localizam a ocupação indígena da região do meio rio Tapajós no período arcaico segundo os autores -, em cerca de 5.000 anos AP (Lisboa e Coirolo 1995).

Gomes (2002, 2008), após ter realizado um estudo da coleção Tapajônica do Museu de Arqueologia e Etnologia da Universidade de São Paulo (MAE/ USP), que objetivou realizar uma minuciosa análise e descrição de diversos atributos da cerâmica e sua descrição, inserir e contextualizar a cerâmica Santarém nos modelos cronológicos de ocupação da região amazônica (entre AD 1.000-1.500), identificou algumas variações estilísticas em meio à cerâmica do estilo Santarém/Aldeia, que poderiam representar "comunidades satélites" interagindo culturalmente com os Tapajó (Nimuendaju 1949).

Para testar essa hipótese, Gomes realizou pesquisas arqueológicas entre 2001 e 2003 registrando 10 sítios arqueológicos na comunidade Parauá, localizada na margem esquerda do rio Tapajós, a, aproximadamente, $120 \mathrm{~km}$ ao sul de Santarém. Os resultados dessa pesquisa fizeram parte de sua tese de doutoramento, com o objetivo de investigar os limites territoriais do domínio Tapajônico. A partir dos resultados de sua pesquisa, sugeriu a existência de 
grupos anteriores aos Tapajós habitando a foz do rio homônimo no período Formativo (entre 3.800-3.600 AP), e os caracterizou como produtores de cerâmica pertencente à Tradição Borda Incisa, menos elaborada em relação à tapajônica, e com uma considerável mobilidade territorial, sugerida pela presença de depósitos arqueológicos pouco profundos. Segundo o autora, a subsistência consistia em atividades extrativistas, caça e pesca além do cultivo de mandioca (Gomes 2005, 2008, 2009).

Nos contextos de ocupação mais recentes (1.320-910 AP), a pesquisadora identificou sítios maiores e com cultura material mais diversificada, em que a cerâmica apresentava traços estilísticos do Horizonte Inciso-Ponteado, amplamente difundido na foz do rio Tapajós e demais áreas da região do baixo Amazonas. Com isto, sugere que a região era ocupada por grupos horticultores anteriores aos Tapajó e que, em um período tardio, a partir do primeiro milênio da era cristã, mantiveram contatos regionais com os tapajó e com os Konduri, sem necessariamente terem sido subordinados ao cacicado tapajônico (Gomes 2008).

A seqüência de ocupação mais recuada para a região do baixo Amazonas foi sugerida pelas pesquisas de Anna Roosevelt em Santarém e Monte Alegre (1987, et al. 1991, 1991b, 1992, et al. 1996). Os achados no sambaqui da Taperinha em Santarém (inicialmente investigado por Hartt e Barbosa Rodrigues no século XIX) e em Monte Alegre (caverna da Pedra Pintada) indicaram que a ocupação humana mais antiga na região do baixo Amazonas remonta a 11.200 AP (Monte Alegre), sendo contemporânea à cultura Clóvis no sul dos Estados Unidos (Roosevelt et al. 1996). A longa sequência estabelecida para a Caverna da Pedra Pintada incluiu ainda ocupações do período arcaico (7.580 a 6.625 AP), formativo (4.000 a 2.000 AP) e, em período mais recente, a ocorrência de cerâmica dos Horizontes Policromo e Inciso-Ponteado.

Pesquisas recentes coordenadas por Roosevelt, Silveira e Schaan no sítio Porto de Santarém (Schaan 2010), e em Belterra (Schaan 2006; Stenborg 2009; Schaan e Lima 2011), têm fornecido informações acerca da ação das sociedades pretéritas e o manejo da paisagem, indicando a presença de numerosos poços (alguns anteriormente descobertos por Nimuendajú) e apontando para a grande quantidade de sítios arqueológicos na região com presença de Terra Preta Arqueológica (TPA).

$\mathrm{Na}$ área do planalto de Belterra, pesquisas arqueológicas vêm sendo realizadas desde 2006 e resultaram no registro de 103 sítios arqueológicos, alguns dos quais foram objeto de escavações (Schaan e Lima 2011). A caracterização estilística dos vestígios recuperados, a investigação do padrão de ocupação dos sítios, suas características morfológicas e funcionais, bem como a distribuição na paisagem, também sugerem similaridades com demais contextos arqueológicos do baixo rio Amazonas, inclusive com os assentamentos localizados nos rios Nhamundá e Trombetas (Schaan 2012).

A cultura material recuperada por estas intervenções também pode ser relacio- 
nada ao Horizonte Inciso-Ponteado, com a ocorrência ainda de estatuetas, tortuais de fuso com incisões geométricas, e vasos de contornos complexos semelhantes aos encontrados em Santarém e atribuídos aos índios Tapajó (Schaan e Lima 2011). Dadas essas similaridades da cultura material, os "moradores dos altos" (parafraseando Nimuendajú 1949), ao que parece, relacionavam-se com os grupos da várzea do rio compartilhando dos mesmos gestos de fabrico de utensílios e símbolos.

Adentrando o rio Tapajós, a, aproximadamente, $260 \mathrm{~km}$ ao sul de Santarém, foi realizado um Programa de Arqueologia nas adjacências das rodovias BR-230 e BR-163, onde foram registradas dezenas de antigos assentamentos indígenas com TPA, e cerâmica do Horizonte IncisoPonteado (Schaan 2006; Schaan e Martins 2009), e por isto correlacionáveis aos grupos da foz da confluência dos rios Tapajós e Amazonas (Martins 2010). No tópico seguinte se apresentam informações mais detalhadas do Programa de Arqueologia mencionado.

Os dados etnohistóricos e arqueológicos aqui apresentados demonstram diversas referências às interações culturais indígenas reportadas por diversos viajantes estrangeiros que percorreram a região durante e após a colonização portuguesa. É importante salientar que, ainda que tragam informações lacônicas sobre comércio, trocas, e sobre uma rede regional de articulações político-administrativas e ideológicas, os registros etnohistóricos parecem corroborar as pesquisas arqueológicas desenvolvidas nas últimas décadas e vice-versa, especialmente sobre a grande densidade populacional à época do contato com os portugueses. Desta forma, essa contextualização etnohistórica e arqueológica é extremamente importante na construção de inferências sobre interações culturais indígenas, uma vez que convergem para o debate arqueológico aqui provocado.

\section{OS SÍTIOS ESTUDADOS ENTRE ITAITUBA E RURÓPOLIS}

No trecho da BR-230 entre Itaituba e Rurópolis há uma grande variabilidade de sítios arqueológicos a céu aberto, oficinas líticas (polidores em afloramentos rochosos de margem de igarapés e rios), áreas com TPA e Terra Mulata, e um sítio com gravuras rupestres. São sítios lito-cerâmicos com grande diversidade de cultura material, sendo que a maior parte dos depósitos arqueológicos situados nas Áreas de Impacto Direto (AID) da rodovia vem sofrendo alterações por conta de atividades agrícolas, passagem de maquinário de terraplenagem, estruturas de fazendas, serrarias, pecuária, etc.

Contudo, apesar do impacto sofrido pelos sítios, foi possível ainda a identificação de estruturas e feições culturais representativas do modo de vida indígena na região, o que impulsionou o uso acadêmico desses dados coletados em contexto de um projeto de licenciamento ambiental.

Os materiais culturais recuperados nos depósitos arqueológicos correspondem a: cerâmica do Horizonte Inciso-Ponteado, instrumentos líticos lascados e poli- 
dos (com destaque para a grande quantidade e variabilidade morfológica de machados polidos), tortuais de fuso, artefatos com representações antropomorfas e zoomorfas, além de restos ósseos e dentes encontrados dentro de vasilhames cerâmicos (Schaan e Martins 2009; Martins et al. 2010).

Com relação à cronologia de ocupação indígena nessa área, datações radiocarbônicas obtidas em material orgânico coletado em três sítios ao longo da BR230 situam a ocupação mais intensa entre AD 1.040 e 1.460, provável período de maior dispersão de cerâmica do Horizonte Inciso-Ponteado. Tais datações são correlacionáveis com os demais contextos datados na região (Roosevelt 1987, 1992; Coirolo 1992; Gomes 2008). O quadro 1 apresenta as datações obtidas para os sítios da BR-230.

Juntamente com a grande quantidade de cultura material, a presença de solos antrópicos é um importante indicador da ocupação pré-colonial na região, bem como da mobilidade indígena entre as áreas da várzea do rio Tapajós e de terra firme, onde estão registrados diversos sítios arqueológicos a dezenas de quilômetros da margem direita desse rio. São depósitos arqueológicos do tipo TPA com diferentes profundidades e extensões que concentram um grande número de vestígios arqueológicos e feições culturais, além daqueles com terra mulata e pequena incidência de vestígios.

Considerando a arbitrariedade das noções de sítio arqueológico que considerem unicamente a dispersão de vestígios que possa ser mensurada horizontal e verticalmente (Dunnel 1992), a definição das porções de TPA como a unidade básica de observação utilizada neste estudo pretende apenas facilitar a apreensão da distribuição dos depósitos arqueológicos e suas localizações em áreas alteradas por aquelas perturbações recentes já mencionadas. Contudo, essas unidades estão aqui sendo consideradas em um contexto mais amplo, regional, que possa esclarecer sobre interações culturais.

Ao se comparar as características de implantação dos sítios arqueológicos na paisagem, parece de fácil apreensão que os grupos sociais de outrora compartilhavam de escolhas análogas quanto ao seu posicionamento no espaço geográfico. Havia aqueles que optaram por estarem próximos ao curso principal do rio; outros que ocuparam os afluentes menores que, no entanto, davam acesso às áreas interioranas com disponibilidade de recursos naturais e provavelmente menor circunscrição ambiental e social (Carneiro 2007); e ainda, os que se deslocavam sazonalmente apenas para lascar e polir artefatos líticos para caçar, pescar, coletar, etc.

Não obstante a preferência por fontes perenes de água, áreas de terra firme sem riscos de alagamentos periódicos, provavelmente próximos a fontes de caça, pesca e extrativismo (dados os materiais culturais encontrados em sítios habitação e relacionáveis a estas práticas), foram comuns àqueles grupos indígenas da região do baixo rio Tapajós (Gomes 2008; Martins 2010; Schaan 2012). Com base em outras pesquisas arqueológicas no baixo rio 
Amazonas, estas escolhas também eram compartilhadas entre coletivos indígenas assentados nas várzeas dos rios Nhamundá e Trombetas (Hilbert 1955; Guapindaia 2008) e na região de Oriximiná (Hilbert e Hilbert 1980).

Tais inferências inclinam-me a pensar em uma cartografia de padrões de escolhas por paisagens, também passível de fundamentar a hipótese de contextos regionais dentro dos quais pessoas interagiam e se comunicavam em largas distâncias.

Utilizando uma escala local, apresento alguns dados sobre o estudo do sítio Alvorada, cuja indústria cerâmica foi investigada no âmbito de uma pesquisa acadêmica desenvolvida no ano de 2010 (Martins 2010). Trata-se de um sítio habitação com TPA localizado no município de Itaituba, e situado a $15 \mathrm{~km}$ da margem direita do rio Tapajós. Este sítio foi registrado na AID da rodovia BR-230 sendo escavado no ano de 2008, no âmbito do Programa de Arqueologia anteriormente citado (Schaan 2009). Localiza-se no km 28 da rodovia e foi seccionado pela abertura da mesma na década de 1970, ocasionando grande impacto aos depósitos arqueológicos. Atualmente, a área é ocupada por estruturas de fazendas e pasto que vêm acelerando a descontextualização de materiais culturais em diversos pontos do tereno.

Assim como os demais sítios das adjacências, o Alvorada está assentado em área elevada de terra firme, próximo a um curso d'água (sem nome). Corresponde a uma faixa de TPA com 24 hectares de área e $40 \mathrm{~cm}$ de profundidade média. Foram identificadas áreas de lixeiras com maior e menor concentração de materiais culturais, na sua maioria fragmentos cerâmicos associados a restos de carvão, material ósseo extremamente friável, artefatos líticos polidos e lascados (Schaan 2009).

Quadro 1

Datações radiocarbônicas dos Sítios Estudados

\begin{tabular}{|c|c|c|c|c|}
\hline $\mathrm{N}^{\circ} \mathrm{Lab}$. & Sítio & Proveniência & Cal (2 sigma) & C14 AP (Conv.) \\
\hline Beta-293286 & Fazenda Cacau & $\begin{array}{l}\text { Unidade N481 } \\
\text { L601 } \\
\text { Nível: } 51-61 \mathrm{~cm}\end{array}$ & $\mathrm{AD} 1420$ a 1460 & $460 \pm 30 \mathrm{AP}$ \\
\hline Beta-293282 & Alvorada & $\begin{array}{l}\text { Unidade N219 } \\
\text { L320 } \\
\text { Nível: } 12-22 \mathrm{~cm}\end{array}$ & $\mathrm{AD} 1260$ a 1400 & $680 \pm 50 \mathrm{AP}$ \\
\hline Beta-293289 & $\begin{array}{l}\text { Serraria } \\
\text { Trombetas }\end{array}$ & $\begin{array}{l}\text { Unidade N559 } \\
\text { L371 } \\
\text { Nível: } 74 \mathrm{~cm}\end{array}$ & AD 1040 a 1220 & $890 \pm 30 \mathrm{AP}$ \\
\hline Beta-293284 & Água Azul & $\begin{array}{l}\text { Unidade N791 } \\
\text { L180 } \\
\text { Nível: } 39-49 \mathrm{~cm}\end{array}$ & BC 1130 a 980 & $2880 \pm 30$ AP \\
\hline
\end{tabular}


O material cerâmico, como mencionado anteriormente, para efeito de comparação, pode ser relacionado ao Horizonte Inciso-Ponteado. A seguir apresentam-se resultados da análise tecnotipológica realizada com este material.

\section{A CULTURA MATERIAL: MARCADORES SOCIAIS}

As características do material cerâmico dos sítios da BR-230 que indicam traços estilísticos com distribuição regional correspondem a aspectos tecnológicos, decorativos e iconográficos similares àqueles descritos por Peter Hilbert (1955) e Guapindaia (2008) para a região dos rios Nhamundá e Trombetas, e por Hilbert e Hilbert (1980) para a região de Oriximiná, tais como: emprego de incisões, ponteados, filetes aplicados, combinados em artefatos modelados com representações antropomorfas e/ou zoomorfas, além do intenso uso de cauixi como antiplástico, ocorrendo por vezes associado a caco moído, caraipé, areia e rocha triturada, cerâmica com pintura vermelha, e pintura vermelha e preta sobre engobo branco.

De modo geral, essas são as variáveis básicas e bastante recorrentes entre as cerâmicas encontradas nos sítios arqueológicos da área de estudo (entorno da rodovia BR-230). Todavia, ocorrem peculiaridades quanto às associações de algumas variáveis consideradas como variações locais.

A amostra de material cerâmico analisado do sítio Alvorada totalizou 4.168 fragmentos com grande variabilidade de formas de vasilhas e padrões decorativos. Para a classificação do material e reconstituições gráficas de formas das vasilhas foram utilizados manuais de uso recorrente nos estudos de coleções arqueológicas da região amazônica (Chmyz 1976), bem como dados de outras pesquisas realizadas no baixo Tapajós (Gomes 2008) e baixo Amazonas (Hilbert 1955; Hilbert e Hilbert 1980), além de estudos etnográficos (Rice 1987; Schiffer e Skibo 1992).

Os atributos tecnológicos identificados demonstraram que a técnica de manufatura das vasilhas era feita por acordelamento (sobreposição de filetes de argila) e posterior alisamento das faces interna e externa das peças. $\mathrm{O}$ preparo da pasta de argila consistia em adicionar antiplásticos orgânicos e minerais cuidadosamente triturados para diminuir a plasticidade da argila ainda úmida, auxiliando na secagem e evitando que a peça quebrasse durante a queima. Foram identificados antiplásticos variados e muitas vezes associados entre si, tais como: cauixi (em maior quantidade do que os demais), caraipé, caco moído, areia e rocha triturada. Regionalmente, confirma-se a preferência pelo uso do cauixi como antiplástico, que ocorre em abundância nos conjuntos cerâmicos do baixo Amazonas (rios Nhamundá e Trombetas) e baixo Tapajós (Hilbert 1955; Hilbert e Hilbert 1980; Gomes 2002, 2008; Martins 2010; Duarte Filho 2010; Schaan 2012).

O uso de antiplástico mineral foi identificado naquelas peças com paredes mais espessas e de maior volume, 
comumente relacionadas a funções de armazenamento e/ou preparo de alimentos (Rice 1987; Schiffer e Skibo 1992). Já o antiplástico orgânico, especialmente o cauixi, foi identificado em peças de menores dimensões e com decorações plásticas e/ou pintadas. Schiffer e Skibo (1992) informam que os antiplásticos orgânicos oferecem maior maleabilidade da pasta de argila ainda úmida, além de oferecerem maior resistência a paredes curvas sendo, portanto, uma melhor escolha para a confecção daqueles vasilhames menores. Na coleção estudada, notouse que aditivos orgânicos eram mais utilizados para a confecção de peças menores, provavelmente usadas para servir bebidas ou comidas, além de vasilhas para cozinhar (Rice 1987).
Quanto à morfologia das vasilhas, foram identificadas 15 formas de recipientes com variação formal bastante representativa. Essas reconstituições objetivaram esclarecer sobre possíveis usos e funções das peças e, para tanto, utilizamos o modelo etnográfico de Rice (1987), que caracterizou os vasilhames a partir de suas formas e volume:

1. Vasilhas para armazenamento: formato fechado, com presença comum de apêndices para movimentos de suspensão e deslocamento. $\mathrm{O}$ engobo e tratamentos de superfície objetivam reduzir a permeabilidade. Baixa freqüência de reposição.

2. Vasilhas para preparação de alimentos: formato simples e aberto, geralmente utilizadas sem aquecimento, que

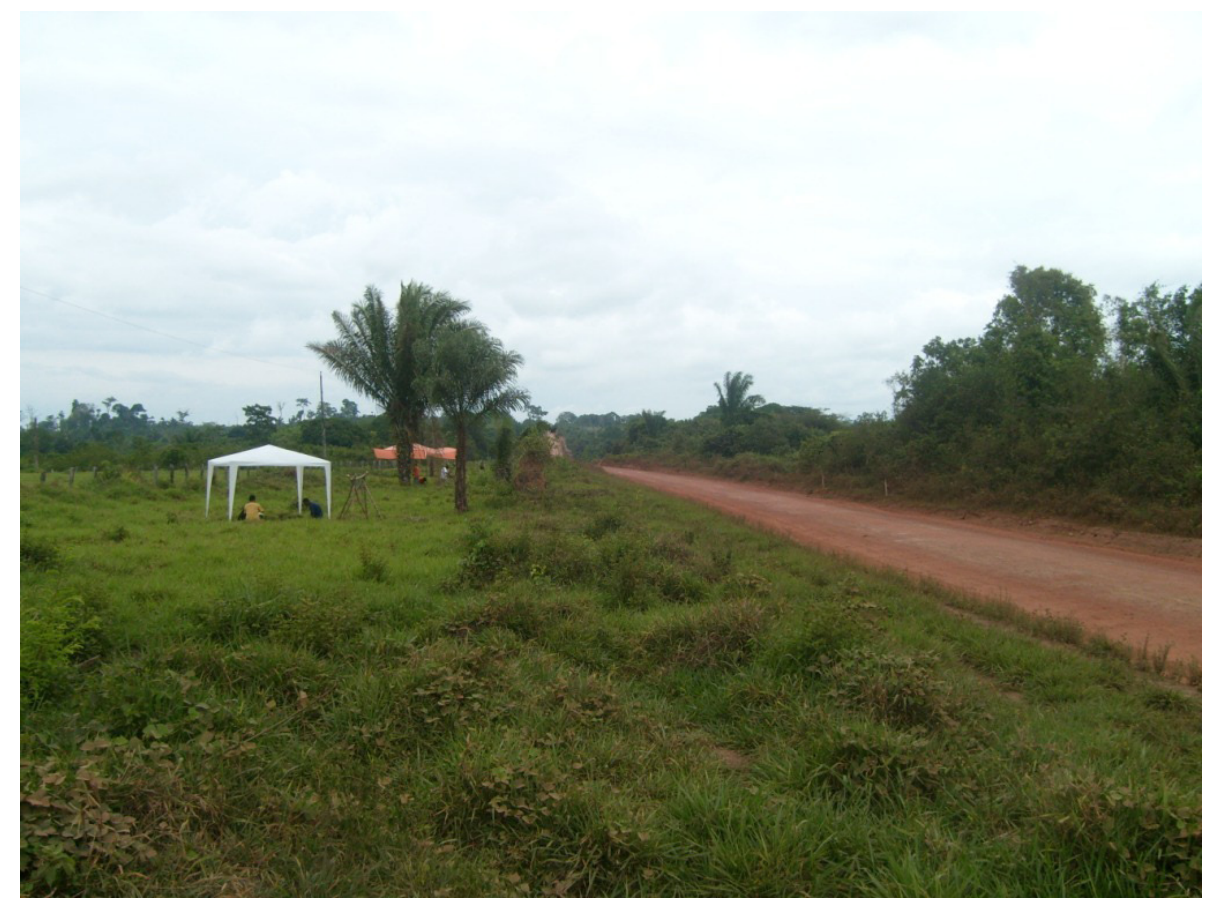

Figura 3 - Sítio Alvorada seccionado pela rodovia BR-230 

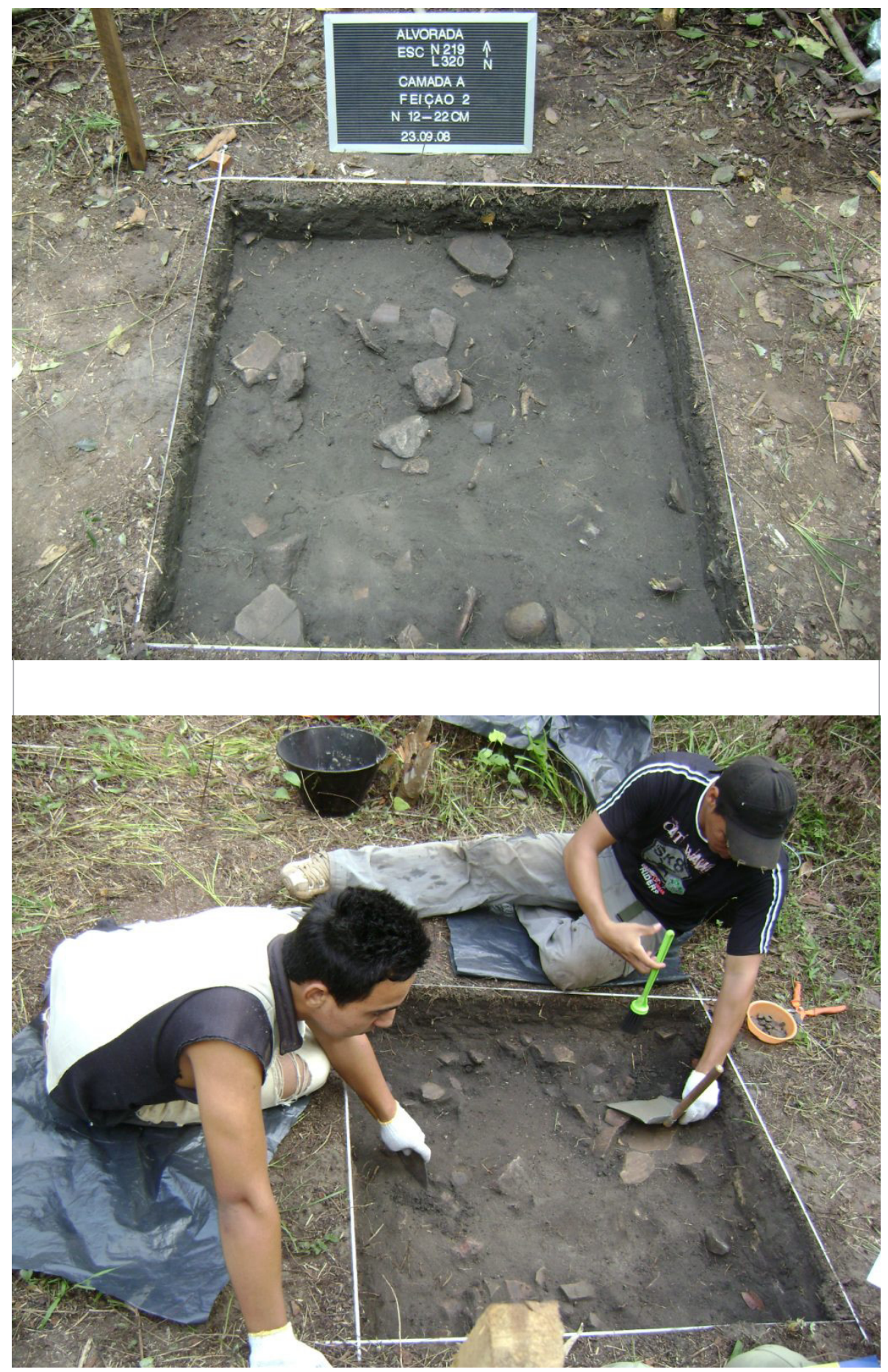

Figura 4 - Escavações no sítio Alvorada 
possuem paredes espessas e pasta densa, a fim de resistir a atividades mecânicas de misturar, triturar, socar, etc.

3. Vasilhas para cozinhar: formas côncavas, globulares ou arredondadas, sem mudança de ângulo no bojo. Geralmente possuem paredes finas para sua resistência ao choque término. Alta freqüência de reposição.
4. Vasilhas para transporte de alimentos ou bebidas: possuem alças, são leves e com formas fechadas.

5. Vasilhas para tostar ou secar: utensilios planos com pouca curvatura na borda.

6. Vasilhas de servir: geralmente de uso individual, com dimensões pequenas, que possuem bases planas ou com suporte para aumento de estabilidade.

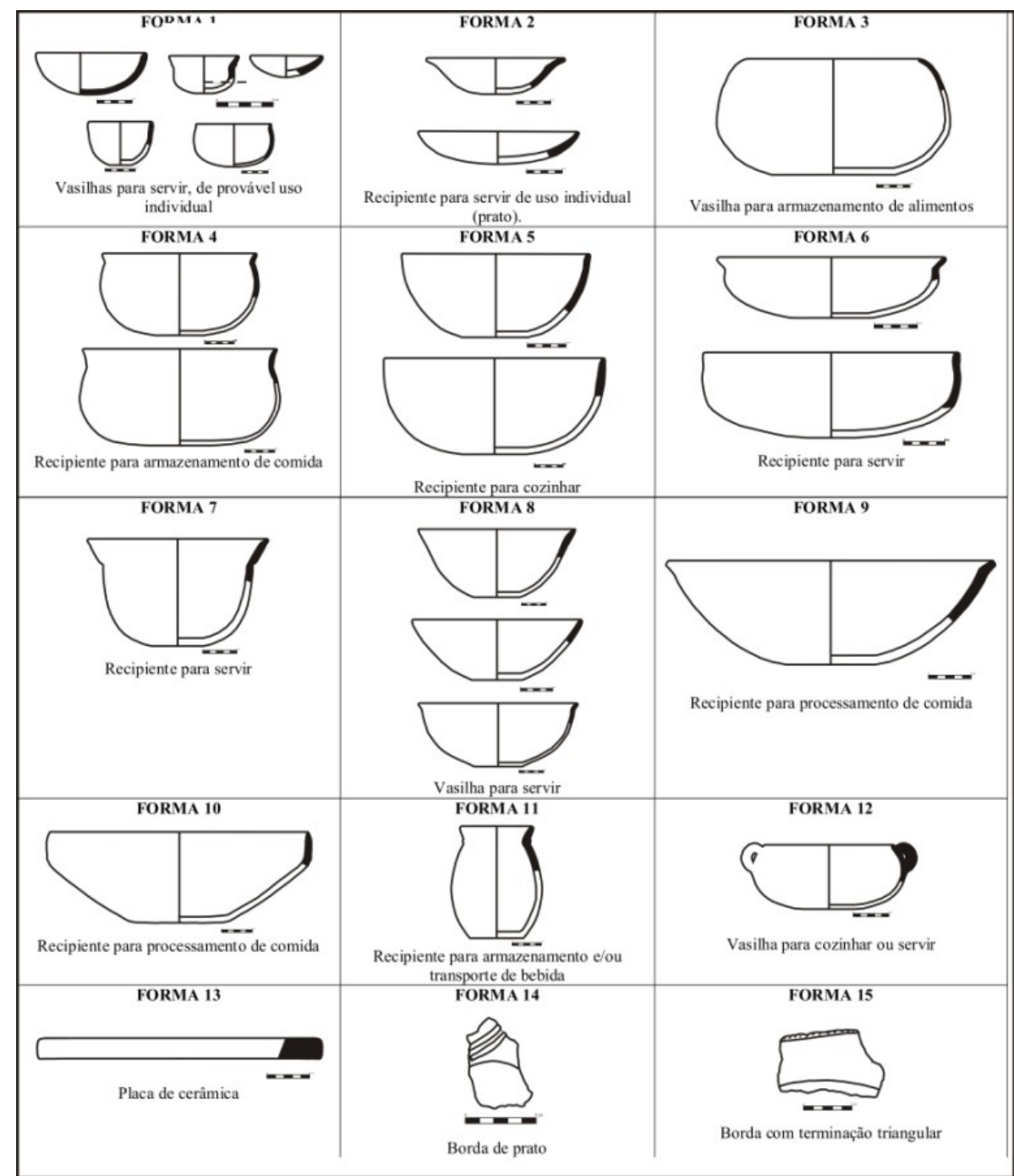

Figura 5 - Formas reconstituídas (desenhos de Cristiane Martins 2010) 
Possuem formas abertas, quase sempre com alças. Decorações com motivos simbólicos.

De acordo com este modelo, as formas identificadas podem ser vistas na figura 5 .

Hilbert (1955; Hilbert e Hilbert 1980) não oferece detalhes sobre as formas de vasilhas identificadas nos sítios arqueológicos dos rios Nhamundá e Trombetas. Gomes (2008), no entanto, apresenta diversas formas reconstituídas, as quais, por comparação, são bastante similares à morfologia das vasilhas do sítio Alvorada, especialmente os recipientes para conter bebidas (forma 11), e para armazenamento e processamento de alimentos (formas $3,4,5$ e 9$)$.

As bordas de prato (formas 14 e 15) são bastante comuns na coleção de cerâmica tapajônica, e no sítio Alvorada ocorreram nos níveis mais superficiais do depósito arqueológico, o que sugere contato, no primeiro milênio da era cristã, entre grupos que teriam ocupado a foz do rio Tapajós e aquelas áreas interioranas e afastadas do seu curso principal.

A forma 13, ainda que representada por um único fragmento na amostra investigada, é bastante comum nos demais sítios encontrados nas adjacências do município de Itaituba, e, ao que parece, foi utilizada como suporte para a confecção de outros vasilhames cerâmicos. Peças similares a esta já foram encontradas em sítios da região da Ilha de Marajó e foram interpretadas como um indicador de produção local de cerâmica (Schaan 2007b).

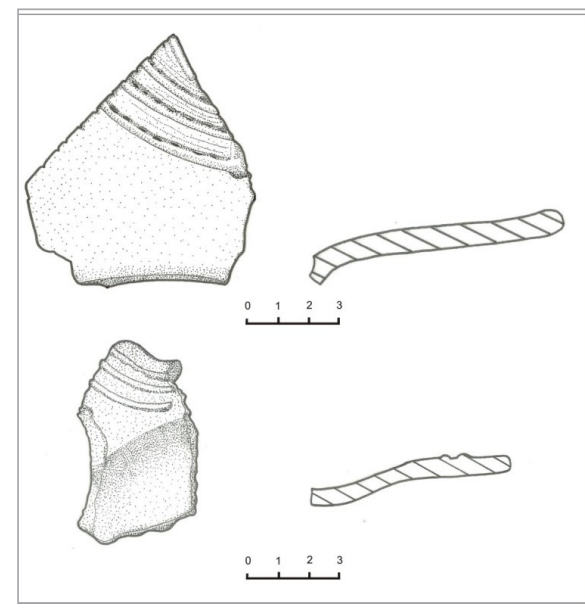

Figura 6 - Exemplares de bordas de pratos

No sítio Alvorada ocorrem diversos recipientes pequenos, aqui entendidos como de uso individual (formas 1, 2 e 8). Já os atributos decorativos, especialmente as decorações plásticas, são bastante similares àqueles descritos por Hilbert (1955) para a região de Oriximiná (Hilbert e Hilbert 1980) e por Guapindaia (2008) para os rios Nhamundá e Trombetas.

Identificou-se o uso frequente de incisões lineares paralelas dentro de áreas triangulares, ponteados, filetes paralelos eventualmente ponteados e apliques em botão, compondo motivos tridimensionais nas paredes dos vasos.

A policromia ocorre na região do rio Tapajós com frequência, apesar de sua presença ser menor em relação às decorações plásticas. É interessante salientar que uma das peças é um gargalo de vaso com pintura bem acabada e semelhante aos vasos tapajônicos (Figura 10).

As similaridades da cultura material entre sítios distantes sugerem escolhas tecnológicas praticadas em nível regional 
que podem ser interpretadas como marcadores sociais. Acredito que isso indique gestos de contato, ou seja, performances compartilhadas, comunicadas e intercambiadas por diversos grupos. A distribuição desses materiais culturais é entendida como performances que refletem um mecanismo de comunicação entre os grupos de outrora, bem como a constituição de um sistema simbólico que pode responder como estratégia de pertencimento a uma identidade regional.

\section{DISCUSSÕES: AS PESSOAS DA PESQUISA}

Acredita-se que a distribuição dos marcadores sociais identificados a partir do estudo da cultura material possa implicar em contemporaneidade dos grupos indígenas, interagindo em amplas distâncias. Inicialmente mencionadas nas informações etnohistóricas desde o século XVI (Teixeira 1639; Bettendorf 1698; Berredo 1718; Carvajal 1941 [1542]; Nimuendaju 1949; Heriarte 1964; Ursua e Aguirre apud Porro 1993; Acuña 1994 [1641]), essas interações indígenas nas regiões do baixo rio Amazonas e baixo rio Tapajós, ao que parece, vêm sendo corroboradas pelas pesquisas arqueológicas desenvolvidas nessa região (Nimuendaju 1949; Gomes 2008; Martins 2010; Filho 2010; Schaan 2012).

Não se está sugerindo com isto que artefatos similares sejam sinônimos de grupos homogêneos sem se considerar mudanças culturais ao longo do tempo, ou mesmo filiações étnicas. Ao contrário, as performances observadas na cultura ma- terial investigada parecem corresponder a uma esfera simbólica a qual estariam vinculados diversos grupos com variações locais, porém que pensavam os mesmos ícones (Barreto 2008). Talvez estas coisas produzidas tivessem a função de agregar pessoas a longas distâncias, como memórias coletivas materializadas na cultura material.

Neste sentido, esta ideia se coaduna com as inferências de Barreto (2008) sobre a agência dos artefatos, as quais considero que podem ser extrapoladas para a região de estudo onde transitavam artefatos como marcadores sociais.

Com base nos dados coletados durante alguns anos de pesquisa na região do baixo rio Tapajós, acredita-se que a noção de fronteira possa representar somente uma convenção do arqueólogo baseada na concepção contemporânea de limites territoriais e administrativos, mas que, ao que parece, não pode ser mensurada apenas pela distribuição de técnicas e características da cultura material, em especial na cerâmica (Schaan 2007a, 2007b). O que me parece ser válido é a reformulação e (re)significação de gestos e performances que se tornam "individuais" em cada grupo que os utilizam. Parece válido também que os gestos utilizados para a produção dos objetos pudessem ser compartilhados em escala regional na forma de marcadores culturais de pertencimento a um sistema coletivo de ideias.

Estas inferências sugerem várias possibilidades já apontadas na bibliografia arqueológica, tais como: características estilísticas diferentes não implicam ausência de contatos; características tecnológicas, morfológicas e decorati- 
vas similares não representam filiação étnica; diferentes traços estilísticos em um mesmo depósito arqueológico não significam propriamente mudanças culturais internas, etc. (Machado 20052006; Schaan 2007a, 2007b).

Como sugeriu Schaan (2007a), os artefatos cerâmicos marajoaras são encontrados largamente distribuídos pela região dos campos da Ilha de Marajó, contudo foram observadas peculiaridades nas iconografias das peças, nas suas formas e nos conteúdos dos enterramentos, que obedeciam a status sociais diferenciados. Este contexto foi entendido como indicador da existência de diversas alianças regionais articuladas e não de uma uniformidade sociopolítica, com peculiaridades locais das urnas funerárias. Sua dispersão por diversos rios teria uma função social de definir uma identidade indígena que não implicava necessariamente em peças padronizadas (Schaan 2007a).

A pesquisadora discute ainda que é possível identificarmos diferentes comportamentos sociais quando do estudo de continuidades e variabilidades de indústrias ceramistas, destacando que não se deve atribuir diferenças em conjuntos de artefatos a fases diferentes (ou seja, a grupos diferentes), ou considerar conjuntos similares e sua dispersão regional como de mesma origem étnica. Com isto, propõe que as análises de indústrias ceramistas devam ser orientadas para priorizarem mudanças culturais, e que considerem que “... processos de produção, circulação, uso e descarte de artefatos possam ser extremamente complexos e modi- ficarem-se juntamente com mudanças sociais e econômicas importantes" (2007b:78).

Desta forma, faz-se necessária a ampliação de abordagens para o trato da cultura material como trocas, emulação, difusão regional de técnicas e estilos, inovações locais e bens de prestígio (2007b), extrapolando os conceitos de migração e difusão que arbitrariamente nortearam pesquisas arqueológicas anteriores (Meggers e Evans 1961).

Incisões, ponteados, entalhes, pinturas, representações de animais e de humanos já foram identificadas nas mais diversificadas indústrias ceramistas de sítios arqueológicos espalhados pelo mundo. Então: como mensurar os limites de comunicação social pela distribuição de traços estilísticos materiais?

Neste aspecto, esse questionamento se ajusta à preocupação demonstrada por Dunnell (1992) sobre as noções discricionárias de sítios arqueológicos, segundo o qual não se pode restringilos ao espaço palpável de dispersão e densidade de artefatos. Crumley e Marquardt (1990), por sua vez, indicam que se devem considerar estas unidades de observação em um sistema social interligado onde não há hierarquias, e sim relações heterárquicas, ou seja, funções sociais complementares, integradas, e significadas na coletividade.

Considero que as relações heterárquicas propostas por Crumley e Marquardt (1990) justificam intercâmbios de ideias e de marcadores sociais em contextos regionais com similaridades de cultura material, uma vez que, a exemplo da 

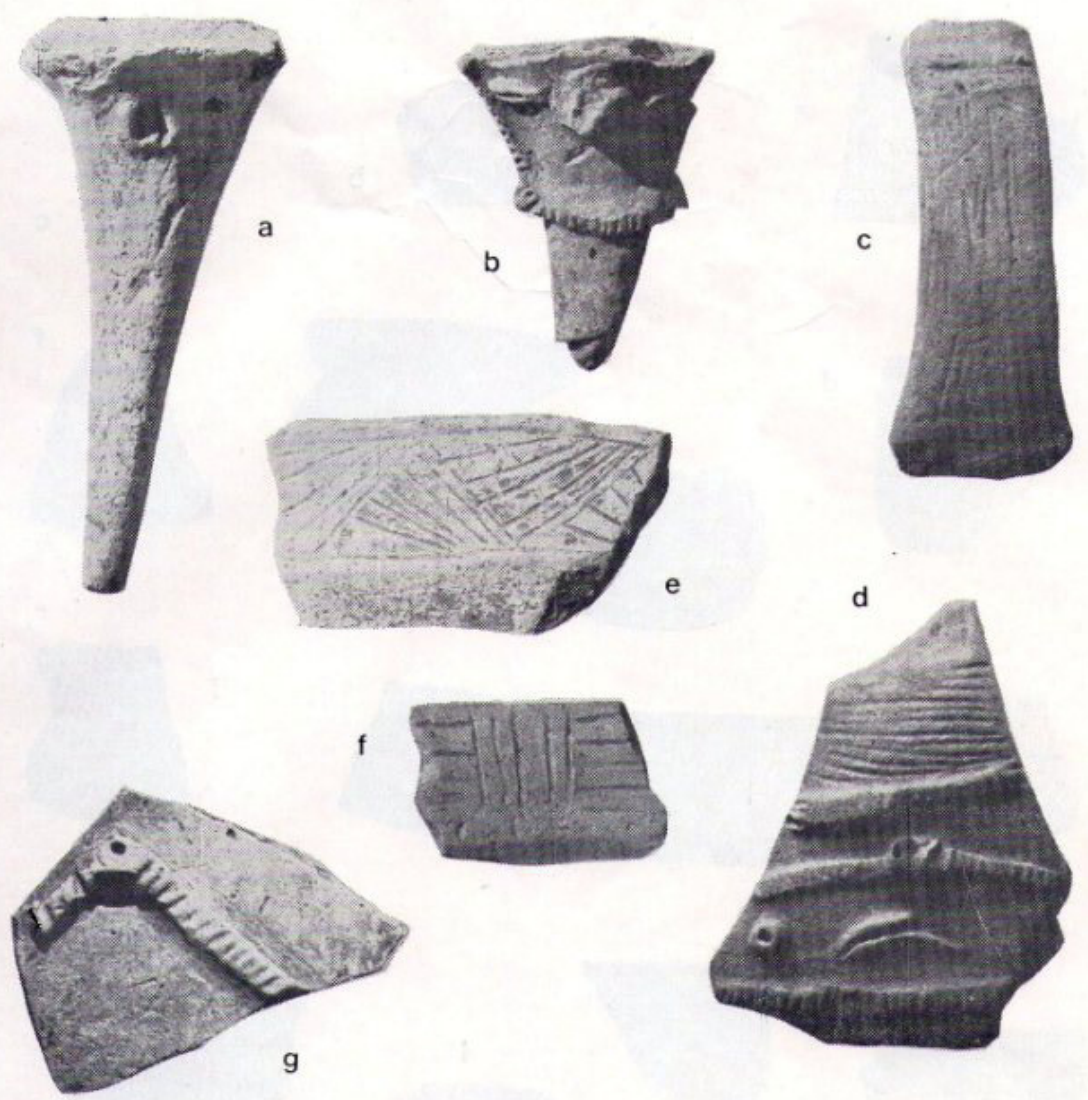

d

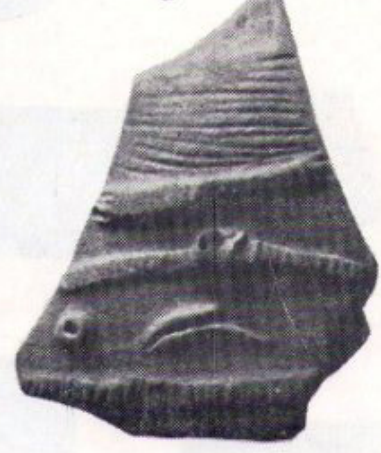

h

$0 \quad 123.4$ E
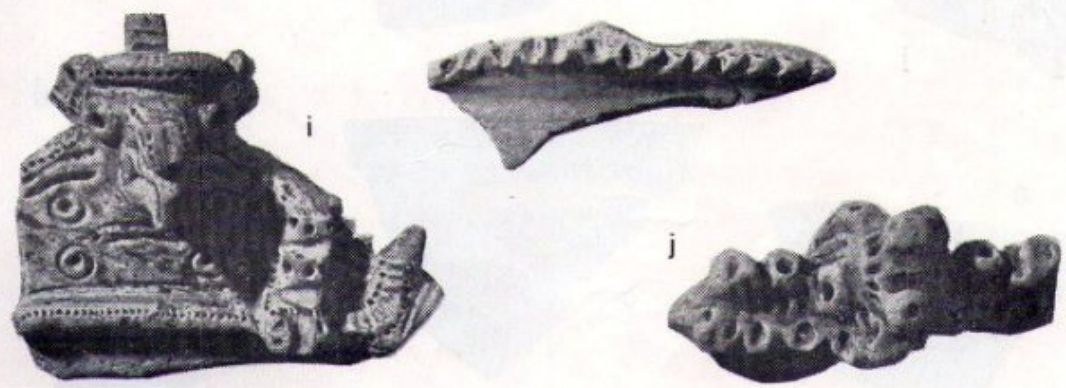

Est. 1 - Cerâmica do complexo Konduri. a, b, bulbos de vasos trípodes; c, d, alças em arco; e, f, inciso; $\mathbf{g} \cdot \mathbf{j}$, modelado-inciso-ponteado.

Figura 7 - Cerâmica dos rios Nhamundá e Trombetas (Hilbert e Hilbert 1980) 
Inst. de Antr. e Etnologia do Pará - PUbl. N. ${ }^{\circ} 9$
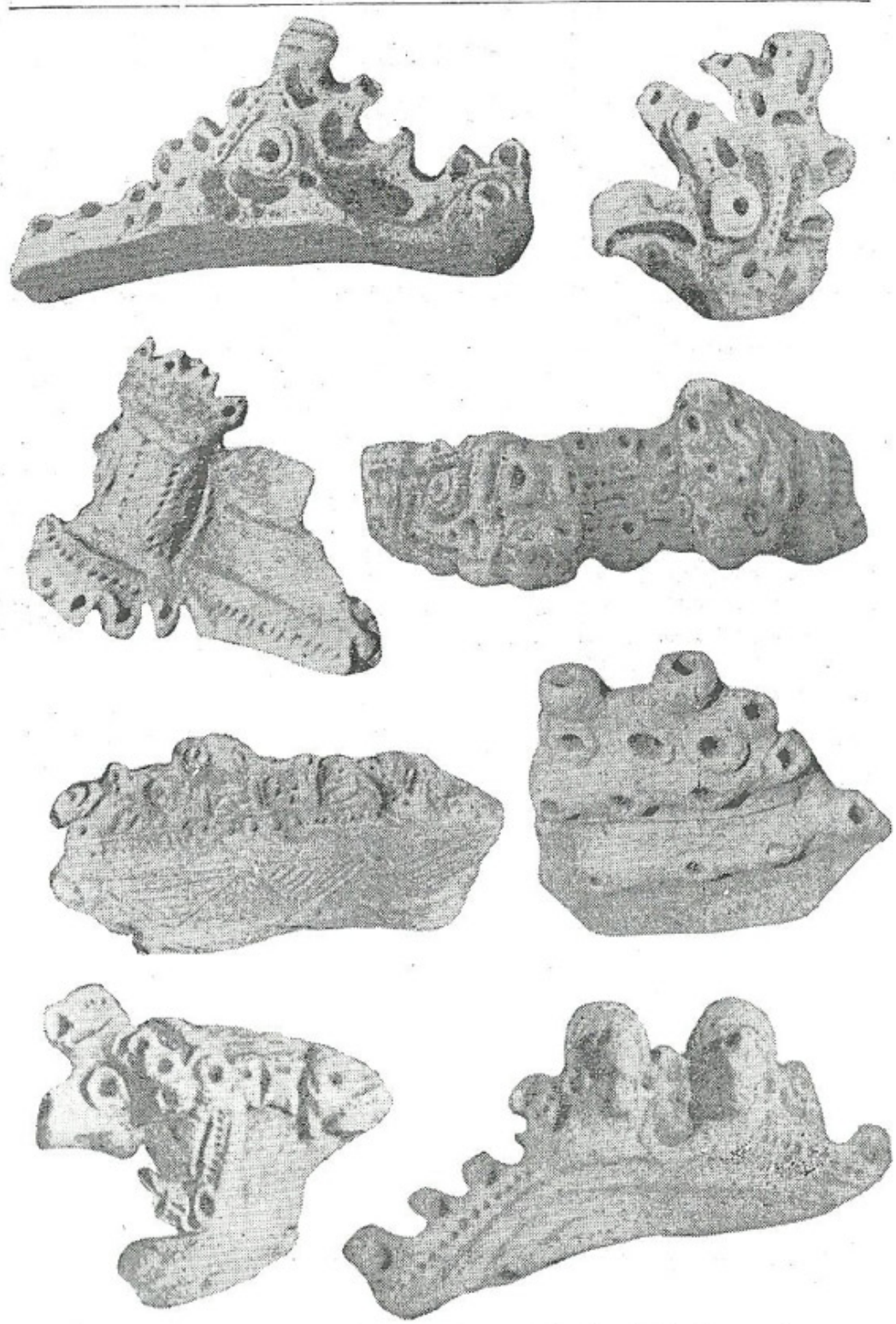

1a fila: Faro (comp. $7,5 \mathrm{~cm}$.$) : Terra Santa (alt. 4,8 \mathrm{cms}$ ) 2. fila: Serrinha (comp. 6,3 cms.); Oriximiná (comp. 10 cms.) 3 a fila: Pimenta (comp. $11 \mathrm{cms}$.); Terra Santa (comp. 6,5 cms.), estílo globular. $4 .^{a}$ fila: Oriximiná (comp. 4.8 cms.); Aibi (comp. $11.5 \mathrm{cms}$ ).

Figura 8 - Cerâmica da região de Oriximiná (Hilbert 1955) 


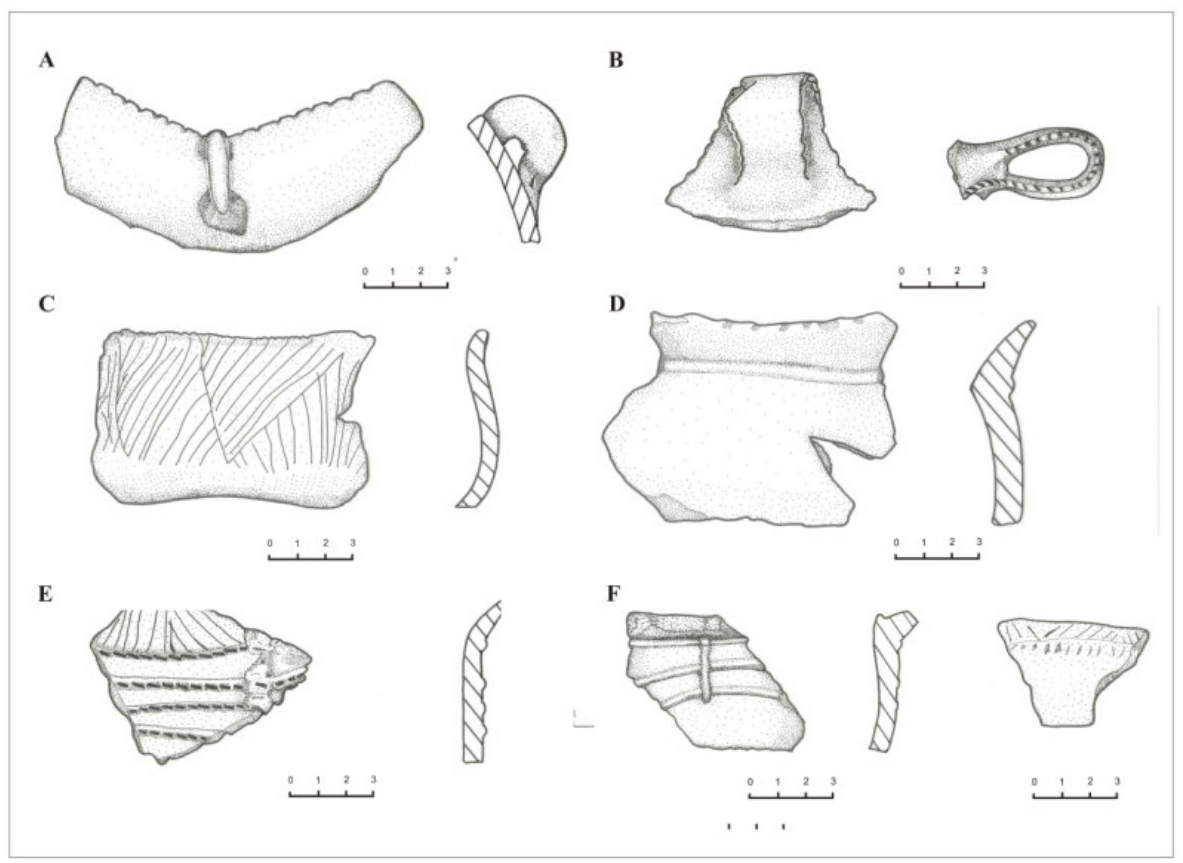

Figura 9 - Tipos de decorações plásticas. A. Frag. de borda com alça; B. Alça; C. Borda com incisões; D. Borda de garrafa; E. Fragmento de parede com filetes aplicados e ponteados; F. Borda com incisões curtas e ungulado. A pintura vermelha é aplicada diretamente em paredes muito bem alisadas das peças, eventualmente combinada com pintura preta sobre engobo branco (em dois fragmentos).

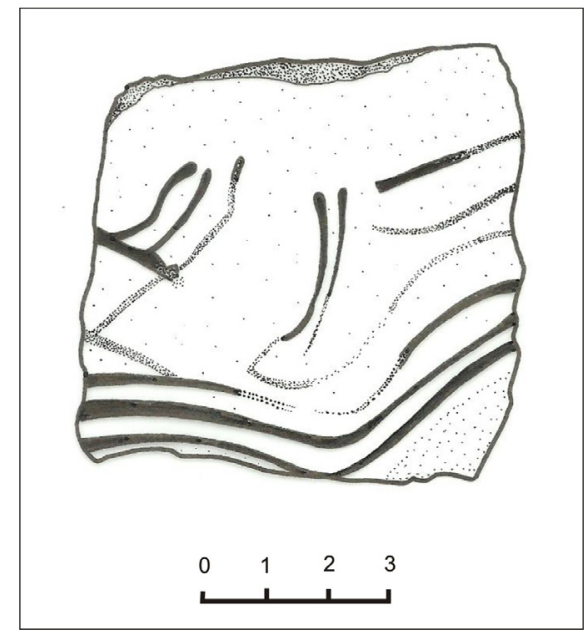

Figura 10- Cerâmica com decoração pintada indústria cerâmica estudada, parece bastante claro que os artefatos representavam agentes culturais que transitam em diferentes contextos.

Desta forma, a ampla distribuição da cerâmica do Horizonte Inciso-Ponteado pode ser pensada como um mecanismo de inclusão de pares, ainda que com características e variações locais.

Tais discussões são valiosas para a arqueologia da região Amazônica por apontarem que o período considerado de complexidade social mais intensa ao final do primeiro milênio da era cristã foi marcado por intensa mobilidade 


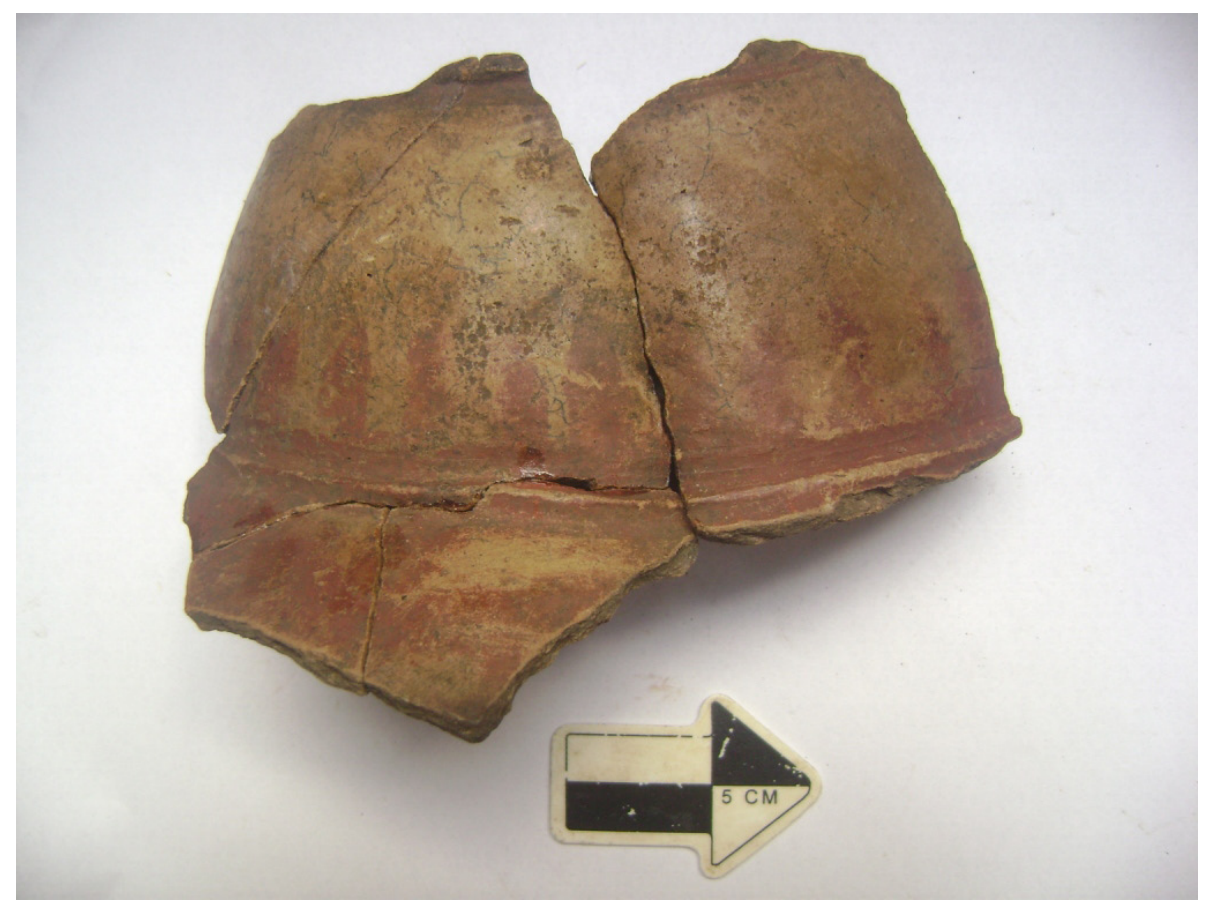

Figura 11- Borda de vaso do tipo gargalo

indígena. Considero que as fronteiras como as pensamos hoje são noções arbitrárias para os contextos arqueológicos, e que a complexidade cultural de outrora pudesse consistir justamente no ato de comunicar e compartilhar sistemas simbólicos entre os pares, ou como postulou Barth: "queda demostrado que ciertas relaciones sociales estables, persistentes, y a menudo importantes, se mantienen por encima de la los límites y, con frecuencia, están basadas precisamente en los status étnicos en dicotomía" (1976a:2).

Acredito que a cartografia das interações culturais na região do baixo rio Tapajós reflita "fronteiras" fluidas (Barth 1976a), que não se configuram como lugares de exclusão ou limites territoriais de atuação, e sim lugares de acertos e auto-afirmações de identidades, trocas, negociações e de vínculos sociais diretamente dependentes da presença dos "outros" habitantes de rios mais distantes.

\section{REFERÊNCIAS}

Acunã, C. de. [1641]. 1994. Novo descobrimento do grande rio das Amazonas. Uruguai: Oltaver S.A. Buenos Libros Activos, Consejería de Educación de La Embajada de España em Brasil.

Barata, F. 1950. A arte oleira dos Tapajó I: considerações sobre a cerâmica e dois tipos de vasos característicos. Publicacóes do Instituto de Antropologia e Etnologia do Pará 2:1-47.

1951. A arte oleira dos Tapajó II: os cachimbos de Santarém. Revista do Museu Paulista 5:183-198. 
1953a. Uma análise estilística da cerâmica de Santarém. Cultura 5:185-205. . 1953b. A arte oleira dos Tapajó III: alguns elementos para a tipologia de Santarém. Publicações do Instituto de Antropologia e Etnologia do Pará 6:1-16.

1954. O muiraquitã e as contas dos Tapajó. Revista do Museu Paulista 8:229-259.

Barbosa Rodrigues, J. 1875. Exploração e estudo do valle do Amazonas e rio Tapajós. Rio de Janeiro: Typographia Nacional.

Barreto, C. 2008. Meios místicos de reproducão social: Arte e estilo na cerâmica funerária da Amazônia antiga. Tese de Doutorado, Programa de PósGraduação em Arqueologia, Museu de Arqueologia e Etnologia/MAE, Universidade de São Paulo, Sâo Paulo, Brasil.

Barth, F. 1976. Los grupos étnicos y sus fronteras. México: Fondo de Cultura Económica.

Bates, H. W. 1979. Um naturalista no rio Amazonas. Belo Horizonte: Itatiaia.

Berredo, B. P. de. 1905 [1718]. Anais históricos do Maranhão: em que se dá notícia do seu descobrimento, e tudo o que mais nele tem sucedido desde o ano em que foi descoberto até o ano de 1718. Tomo I, $3^{\mathrm{a}}$ edição. Florença: Typographia Barbera.

Bettendorf, J. F. 1909. Crônica da missão dos padres da companhia de Jesus no estado do Maranhão (1625-1698). Revista do Instituto Histórico e Geográfico Brasileiro, vol. 119.

Carvajal, G. de. 1941 [1542]. Descobrimento do rio de Orellana. Tradução de C. de MelloLeitão. São Paulo: Editora Nacional.

Chmyz, I. 1976. Terminologia arqueológica brasileira para a cerâmica. Cadernos de Arqueologia. Museu de Arqueologia e Artes Populares, Paranaguá, Universidade Federal do Paraná.

Coirolo, A. D. 1992. Povoamento pré-histórico e etnohistórico da microregião do Tapajós e sua relação com meio ambiente. Relatório preliminar de via- gem a Itaituba, Belém: MPEG. Inédito.

Condamine, C. M. de la. 2000. Viagem na América meridional descendo o rio das Amazonas (1743-1744). Vol. I e II. Brasília: Senado Federal.

Corrêa, C. G. 1965. Estatuetas de cerâmica na cultura Santarém. Publicações do Musen Paraense Emílio Goeldi 4.

Coudreau, H. 1977. Viagem ao Tapajós. São Paulo: Livraria Itatiaia.

Crumley, C. L. e W. Marquardt. 1990. Landscape: a unifying concept in regional analysis, in Interpreting space: GIS and archaeology. Editado por K. Allen, S. Green \& E. Zubrow, pp. 74-79. London: Taylor and Francis.

Duarte Filho, A. 2010. Do rio Nhamundá ao Amazonas e Tapajós: uma rota transversal pré-colonial na região do Baixo Amaz̧onas. Monografia de Especialização em Arqueologia. Instituto de Filosofia e Ciências Humanas, Universidade Federal do Pará, Belém, Brasil.

Dunnell, R. C. 1992. The notion site, in Space, time, and archaeological landscapes. Editado por J. Rossignol \& L. Wandsnider, pp. 21-42. New York: Plenum Press.

Florence, H. 2007 (ed.). Viagem fluvial do Tietê ao Amazonas de 1825 a 1829. Brasília: Senado Federal, Conselho Editorial, vol. 93.

Gell, A. 1992. The technology of enchantment and the enchantment of technology, in Anthropology, art and aesthetics. Editado por J. Coote \& A. Shelton, pp. 40-63. Oxford: Clarendon Press.

Gomes, D. M. C. 2002. Cerâmica arqueológica da Amarônia: vasilhas da colecão tapajônica MAE-USP. São Paulo: FAPESP/EDUSP/ Imprensa Oficial de São Paulo.

2005. Análise dos padrões de organização comunitária no Baixo Tapajós: o desenvolvimento do Formativo na área de Santarém, PA. Tese de Doutorado, Museu de Arqueologia 
e Etnologia, Universidade de São Paulo, São Paulo, Brasil.

2008. Cotidiano e poder na Amazônia

pré-colonial. São Paulo: Eudsp/FAPESP.

2009. Os Tapajó e os outros, in

Cenários regionais na Arqueologia brasileira. Organizado por W. F. Morales \& F. P. Moi, pp. 235-251. São Paulo: Annablume.

2010. Os contextos e os significados da arte cerâmica dos Tapajó, in $A r$ queologia Amazônica. Vol.1. Organizado por E. Pereira \& V. Guapindaia, pp. 213-234. Belém: Museu Paraense Emílio Goeldi.

Guapindaia, V. 2008. Além da margem do rio: as ocupações Konduri e Pocó e na região de Porto Trombetas, $P A$. Tese de Doutorado, Museu de Arqueologia e Etnologia, Universidade de São Paulo, São Paulo, Brasil.

Hartt, C. F. 1885. Contribuições para a ethnologia do Valle do Amazonas. Archivos do Museu Nacional 6:1-174.

Heriarte, M. de. 1964 [1874]. Descriçam do estado do Maranham, Para, Corupa, rio das Amazonas. Viena: Carlos Gerold.

Hilbert, P. P. 1955. A cerâmica arqueológica da região de Oriximiná. Publicações do Instituto de Antropologia e Etnologia do Pará. Publicação $n^{\circ}$ 9. 76p.

Hilbert, P. P. \& K. Hilbert. 1980. Resultados preliminares da pesquisa arqueológica nos rios Nhamundá e Trombetas, baixo Amazonas. Boletim do Museu Paraense Emílio Goeldi 75:1-15.

Lisboa, P. e A. Coirolo. 1995. Notas sobre implementos indígenas com madeira de 5.000 anos da microrregião do Tapajós, Pará. Boletim do Museu Paraense Emílio Goeldi Série Botânica 11(1):7-17.

Machado, J. S. 2005-2006. O potencial interpretativo das análises tecnológicas: um exemplo amazônico. Revista do Museu de Ar- queologia e Etnologia 15-16:87-111.

Martins, C. M. P. 2010. Ocupações humanas pré-coloniais na bacia do baixo rio Tapajós, Amazônia brasileira. Monografia de Especialização em Arqueologia, Instituto de Filosofia e Ciências Humanas, Universidade Federal do Pará, Belém, Brasil.

. 2012. Os moradores do centro: Ocupações indígenas pré-coloniais no baixo Tapajós, in Arqueologia, patrimônio e multiculturalismo na beira da estrada: Pesquisando ao longo das Rodovias Transamazônica e SantarémCuiabá, Pará. Editado por D. P. Schaan. Belém: JKNoronha, no prelo.

Martins, C. M. P., A M. A. Lima, D. P. Schaan, I. M. A. Bezerra \& W. F. V. Silva. 2010. Padrões de sepultamento na periferia do domínio Tapajó. Amazônica 2(1):167-171.

Meggers, B., e C. Evans. 1961. An experimental formulation of horizon styles in the tropical forest of South America, in Essays in pre-columbian art and archaeology. Editado por S. Lothrop, pp. 372-88. Cambridge: Harvard University Press.

Menéndez, M. A. 1981-82. Uma contribuição para a etnohistória da área Tapajós-Madeira. Revista do Museu Paulista 28:289-388.

Neves, E. G. 2008. Ecology, ceramic chronology and distribution, long term history, and political change in the Amazonian floodplain, in Handbook of South American Archaeology. Editado por H. Silverman \& W. H. Isbell. New York: Springer.

Nimuendajú, C. 1949. Os Tapajó. Boletim do Museu Paraense Emílio Goeldi 10:93-106.

Nimuendajú, C. 2004. In pursuit of a past Amazon: archaeological researches in the Brazilian Guyana and in the Amazon region. Goteborg. Ethnological Studies 45, Elanders Infologistik Vast AB.

Palmatary, H. C. 1939. Tapajo pottery. Etnologiska Studier 8:1-136. 
1960. The archaeology of the lower Tapajos valley: Brazil. Transactions of the American Philosophical Society. New Series 50.

Perota, C. 1979. Projeto PRONAPABA. Vitória: Universidade Federal do Espírito Santo. Relatório de Campo. Inédito.

1982. Projeto PRONAPABA. Vitória: Universidade Federal do Espírito Santo. Relatório de Campo. Inédito.

Porro, A. 1993. As crônicas do rio Amazonas: notas etnobistóricas sobre as antigas populações indígenas da Amazônia. Petrópolis: Vozes.

Reis, A. C. F. 1993. Limites e demarcações na Amazônia brasileira: fronteira colonial com a Guiana Francesa. Vol. 1. Belém: SECULT.

2003. A Ocupação portuguesa do vale amazônico, in História geral da civilização brasileira: do descobrimento à expansão territorial. Tomo 1: A Época Colonial. Organizado por S> B. Holanda, pp. 283-299. Rio de Janeiro: Bertrand Brasil.

Rice, P. 1987. Pottery analysis: a sourcebook. Chicago: University of Chicago Press.

Roosevelt, A. C. 1987. Chiefdoms in the Amazon and Orinoco, in Chiefdoms in the Americas. Editado por R. Drennan \& C. Uribe, pp 153-185. Lanham: University Press of America.

1991. Relatório preliminar sobre o levantamento e escavações na Caverna da Pedra Pintada, Monte Alegre, Pará, Brasil. Segunda etapa de campo do projeto arqueológico Santarém.

1992. Arqueologia Amazônica, in História dos indios no Brasil. Organizado por M. C. Cunha, pp. 53-86. São Paulo: Cia. das Letras.

Roosevelt, A. C, R. A. Housley, M. Imazio da Silveira, S. Maranca \& R. Johnson. 1991. Eighth millennium pottery from a prehistoric shell midden in the Brazilian Amazon. Science 254:1621-1624.

Roosevelt, A. C., M. Lima da Costa, C. L.
Machado, M. Michab, N. Mercier, H. Valladas, J. Feathers, W. Barnett, M. Imazio da Silveira, A. Henderson, J. Silva, B. Chernoff, D. S. Reese, J. A. Holman, N. Toth e K. Schick. 1996. Paleoindian cave dwellers in the Amazon: the peopling of the Americas. Science 272:373-384.

Schaan, D. P. 2006. Diagnóstico do patrimônio arqueológico na área de Influência da Rodovia BR-163: Trecho Santarém-Rurópolis. Relatório Técnico. Belém, UFPA. Inédito.

.2007a. Os Filhos da Serpente: Rito, mito e subsistência nos cacicados da Ilha de Marajó. International Journal of South American Archaeology 1:50-56.

2007b. Uma janela para a história pré-colonial da Amazônia: olhando além e apesar - das fases e tradições. Boletim do Museu Paraense Emílio Goeldi 2(1):77-89.

2009. Programa de Identificação e salvamento do Patrimônio Arqueológico na BR-163 (Guarantã do Norte/Entroncamento BR-230) e BR-230 (Miritituba/Rurópolis). Belém: Universidade Federal do Pará. Relatório de Campo Semestral (Ago-Dez/2008). Inédito.

2010. Relatório Final de Salvamento do sítio PA-ST42: Porto de Santarém. Belém: UFPA. Inédito.

2012. Sacred geographies of ancient Amazonia. Historical ecology of social complexity. Walnut Creek: Left Coast Press.

Schaan, D. P. \& C. M. P. Martins. 2009. Programa de Identificação e Salvamento do Patrimônio Arqueológico na BR-163 (Guarantã do Norte/ Entroncamento BR-230) e BR-230 (Miritituba/Rurópolis). Relatório de Campo: Salvamento Arqueológico na BR-230: Trecho Km30 a Rurópolis. Belém: Universidade Federal do Pará. Inédito.

Schaan, D. P. \& e A. M. A. Lima. 2011. Programa de Arqueologia \& Educaşão Patrimonial BR-163: Santarém-Rurópolis; BR-230/PA: Di- 
visa TO/PA à Rurópolis (Excluindo trecho Altamira-Medicilandia); BR422: Trecho: Novo Repartimento-Tucuruí. $5^{\circ}$ Relatório Parcial - Rodovia BR-163: Trecho Santarém-Rurópolis. Belém: Universidade Federal do Pará. Inédito.

Schiffer, M. B., \& J. Skibo. 1992. Theory and experiment in the study of technical change, in Technological perspectives on behavioral change. Editado por M. B. chiffer \& M. B. Tucson, pp. 40-76. Tucson: University of Arizona Press.

Simões, M. F., \& F. Araújo-Costa. 1978. Áreas da Amazônia Legal para cadastro e pesquisa de sítios arqueológicos. Belém: Museu Paraense Emílio Goeldi.

Stenborg, P. 2009. Points of convergence, routes of divergence. Some considerations based on Curt Nimuendajú's archaeological work in the Santarém-Trombetas area and at Amapá, in Anthropologies of Guayana. Cultural spaces in northeastern Amazonia. Editado por N. L. Whitehead \& A. W. Alemán, pp. 55-73. Tucson: University of Arizona Press.

Teixeira, P. 1950 [1639]. Relación del general Pedro Tejeira de el rio de las Amazonas para el Sr. Presidente, in O significado da expedicão de Pedro Teixeira à luz de novos documentos. Anais do IV Congresso de História Nacional. Editado J. Cortezão, pp. 173-204. Rio de Janeiro.

Recebido em 30/01/2012.

Aprovado em 05/03/2012. 